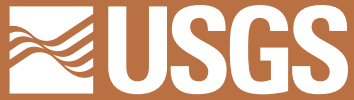

science for a changing world

Prepared in cooperation with the South Carolina Department of Transportation

Field Manual for Identifying and Preserving High-Water Mark Data

Open-File Report 2017-1105

U.S. Department of the Interior U.S. Geological Survey 
Cover. High-water mark from the October 2015 flooding in Columbia, South Carolina. The photograph was taken by U.S. Geological Survey personnel on October 8, 2015, from a home near Kinley Creek. 


\section{Field Manual for Identifying and Preserving High-Water Mark Data}

By Toby D. Feaster and Todd A. Koenig

Prepared in cooperation with the South Carolina Department of Transportation

Open-File Report 2017-1105

U.S. Department of the Interior

U.S. Geological Survey 


\section{U.S. Department of the Interior \\ RYAN K. ZINKE, Secretary}

\section{U.S. Geological Survey \\ William H. Werkheiser, Acting Director}

\section{U.S. Geological Survey, Reston, Virginia: 2017}

For more information on the USGS - the Federal source for science about the Earth, its natural and living resources, natural hazards, and the environmentvisit https://www.usgs.gov or call 1-888-ASK-USGS.

For an overview of USGS information products, including maps, imagery, and publications, visit https://store.usgs.gov.

Any use of trade, firm, or product names is for descriptive purposes only and does not imply endorsement by the U.S. Government.

Although this information product, for the most part, is in the public domain, it also may contain copyrighted materials as noted in the text. Permission to reproduce copyrighted items must be secured from the copyright owner.

Suggested citation:

Feaster, T.D., and Koenig, T.A, 2017, Field manual for identifying and preserving high-water mark data: U.S. Geological Survey Open-File Report 2017-1105, 67 p., https://doi.org/10.3133/ofr20171105.

ISSN 0196-1497 (print)

ISSN 2331-1258 (online)

ISBN 978-1-4113-4177-7 


\section{Preface}

The information in this field manual is intended as a quick reference for those involved with flagging and documenting high-water marks. Before going to the field, users are encouraged to familiarize themselves with the more detailed information provided in U.S. Geological Survey Techniques and Methods 3-A24 "Identifying and Preserving High-Water Mark Data" (Koenig and others, 2016), which is available at https://doi.org/10.3133/tm3A24 and is for sale by the U.S. Geological Survey, Science Information Delivery, Box 25286, Federal Center, Denver, Colorado 80225.

Unless stated otherwise, all photographs were taken by USGS personnel. 


\section{Contents}

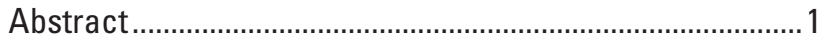

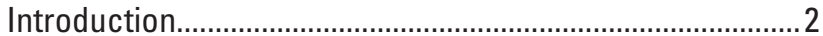

Purpose of High-Water Marks............................................. 3

Suggested Field Equipment for High-Water Mark

Data Collection

Types of High-Water Marks ................................................ 10

Rules of Thumb for Finding High-Water Marks ...................21

Location of High-Water Marks ...........................................22

Flagging and Documenting High-Water Marks ...................23

Evaluating High-Water Marks ............................................ 28

Best Practices-Developing an Eye for Finding

High-Water Marks and Avoiding Pitfalls ................29

References Cited.................................................................. 40

Appendix 1. High-Water Mark Examples .......................... 43

Seed Lines......................................................................... 43

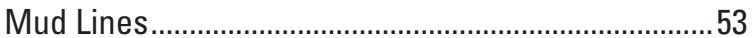

Debris Snags............................................................... 59

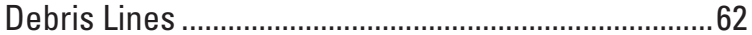

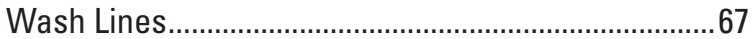




\section{Figures}

1. Definition sketch showing favorable locations for high-water marks

2. Well-defined seed lines on large tree trunks

3. Examples of mud lines

4. Examples of debris lines.

5. A line of debris collected along a chain-link fence

6. Diagrams illustrating how debris is deposited.

7. Preparing to survey a cut line in a sand/clay bluff

8. Examples of flagging a wash line.

9. Examples of markers for recording high-water marks.

10. Field personnel using a carpenter's level to transfer high-water marks

11. A debris pile in a tree with a snake napping in an upper branch

12. A road washout just downstream from a livestock farm on St. Vrain Creek, Colorado.......32

13. A debris snag and two seed lines. 33 
14. Structures with high-water marks that have likely moved during the flood, making peak water surface uncertain ..................35

15. Seed lines.

16. A laptop computer showing a plot of high-water marks created in the field 39

1-1. Seed line with uncertainty of \pm 0.01 foot.............. 43

$1-2$. Seed line with uncertainty of \pm 0.02 foot............... 44

1-3. Seed line with uncertainty of \pm 0.02 foot................ 45

1-4. Seed line with uncertainty of \pm 0.02 foot............... 46

1-5. Seed line with uncertainty of \pm 0.02 foot.............. 47

1-6. Seed line with uncertainty of \pm 0.02 foot............... 48

1-7. Seed line with uncertainty of \pm 0.05 foot............... 49

$1-8$. Seed line with uncertainty of \pm 0.05 foot...............50

1-9. Seed line with uncertainty of \pm 0.05 foot...............51

1-10. Seed line with uncertainty of \pm 0.2 foot.................52

1-11. Mud line with uncertainty of \pm 0.02 foot................53

1-12. Mud line with uncertainty of \pm 0.02 foot................54

1-13. Mud line with uncertainty of \pm 0.05 foot.................55

1-14. Mud line with uncertainty of \pm 0.05 foot................56

$1-15$. Mud line with uncertainty of \pm 0.3 foot.................57

1-16. The mud lines on the trees show a clear pattern when viewed from a distance 
1-17. Debris snag with uncertainty of \pm 0.05 foot..........59

1-18. Debris snag with uncertainty of \pm 0.1 foot............60

$1-19$. Debris snag with uncertainty of \pm 0.2 foot............61

1-20. Debris line with uncertainty of \pm 0.1 foot .............62

1-21. Debris line with uncertainty of \pm 0.1 foot .............63

1-22. Debris line with uncertainty of \pm 0.2 foot.............64

1-23. Debris line with uncertainty of \pm 0.3 foot ..............65

1-24. Debris line with uncertainty of \pm 1 foot.................66

$1-25$. Wash line with uncertainty of \pm 0.2 foot ..............67

\section{Tables}

1. Publications of indirect measurement techniques including the proper location of high-water marks.................................. 4

2. High-water mark uncertainty shorthand 


\section{Conversion Factors}

U.S. customary units to International System of Units

\begin{tabular}{lll}
\hline \multicolumn{1}{c}{ Multiply } & \multicolumn{1}{c}{ By } & \multicolumn{1}{c}{ To obtain } \\
\hline & Length & \\
\hline inch (in.) & 2.54 & centimeter $(\mathrm{cm})$ \\
foot (ft) & 0.3048 & meter $(\mathrm{m})$ \\
\hline
\end{tabular}

\section{Datum}

Vertical coordinate information is referenced to the North American Vertical Datum of 1988 (NAVD 88). 


\section{Field Manual for Identifying and Preserving High-Water Mark Data}

By Toby D. Feaster and Todd A. Koenig

\section{Abstract}

This field manual provides general guidance for identifying and collecting high-water marks and is meant to be used by field personnel as a quick reference. The field manual describes purposes for collecting and documenting high-water marks along with the most common types of high-water marks. The manual provides a list of suggested field equipment, describes rules of thumb and best practices for finding high-water marks, and describes the importance of evaluating each high-water mark and assigning a numeric uncertainty value as part of the flagging process. The manual also includes an appendix of photographs of a variety of high-water marks obtained from various U.S. Geological Survey field investigations along with general comments about the logic for the assigned uncertainty values. 


\section{Introduction}

Proficient high-water mark (HWM) data collection contributes to a better understanding of the flooding process and reduces risk by improving the ability to estimate flood probability. U.S. Geological Survey (USGS) Techniques and Methods, book 3, chapter A24 "Identifying and Preserving High-Water Mark Data" (Koenig and others, 2016) provides detailed guidance for high-water mark (HWM) identification, including marks left behind in natural and man-made environments by tranquil and rapid flowing water. Their report also provides guidance identifying the best HWMs and assessing the uncertainty of a given mark by including pitfalls and challenges associated with various types of flood evidence (Koenig and others, 2016).

The purpose of this field manual is to provide a quick reference document that can aid field personnel in the identification, documentation, and archival of HWM data. The primary reference for the information included in this field manual is Koenig and others (2016). Much of the material is generic with respect to region of the country, but most of the example photographs are from the Southeastern United States. It is assumed that the user of this field manual will have thoroughly reviewed the more-detailed information provided in Koenig and others (2016) before to deploying to the field to identify and document HWMs. 


\section{Purpose of High-Water Marks}

There are varied reasons for collecting and documenting HWMs. Some of the most common reasons are as follows.

- Documentation of high-flow events. - High-flow events are documented for many purposes, one of the most important being to improve models used to predict the severity of future floods (U.S. Geological Survey, 2017).

- Indirect measurements of peak flows.-Available resources allow direct measurements to be made only at a few locations during a major flood; however, peak flows can sometimes be estimated using indirect determinations of discharge after the flood has passed. The number of HWMs needed for indirect measurements to be made is site dependent. Details on the various indirect methods are available from the references listed in table 1 . The following are general suggestions that may be helpful when collecting HWMs along the selected reach for a slope-area indirect measurement. Mild water-surface slopes, such as those in low-gradient streams in the plains and coastal regions, may be represented accurately with 7 to 10 HWMs per 100 feet of reach. The frequently changing water-surface slope of high gradient 
streams, such as those in mountainous regions, may require 20 to $30 \mathrm{HWMs}$ per 100 feet of reach.

Table 1. Publications of indirect measurement techniques including the proper location of high-water marks.

\begin{tabular}{|c|c|c|}
\hline Book-chapter & Title (author, year) & $\begin{array}{l}\text { Indirect measure- } \\
\text { ment type or purpose }\end{array}$ \\
\hline TWRI 3-A1 & $\begin{array}{l}\text { General field and office } \\
\text { procedures for indirect } \\
\text { discharge measure- } \\
\text { ments (Benson and } \\
\text { Dalrymple, 1967) }\end{array}$ & $\begin{array}{l}\text { General indirect } \\
\text { measurement } \\
\text { guidelines. }\end{array}$ \\
\hline TWRI 3-A2 & $\begin{array}{l}\text { Measurement of peak } \\
\text { discharge by the slope- } \\
\text { area method (Dalrym- } \\
\text { ple and Benson, 1968) }\end{array}$ & $\begin{array}{c}\text { Reasonably straight, } \\
\text { open channels. }\end{array}$ \\
\hline TWRI 3-A3 & $\begin{array}{l}\text { Measurement of peak } \\
\text { discharge at culverts } \\
\text { by indirect method } \\
\text { (Bodhaine, 1968) }\end{array}$ & Culverts. \\
\hline TWRI 3-A4 & $\begin{array}{l}\text { Measurement of peak } \\
\text { discharge at width } \\
\text { contractions by indirect } \\
\text { methods (Matthai, } \\
\text { 1967) }\end{array}$ & $\begin{array}{l}\text { Open channel width } \\
\text { contractions (for } \\
\text { example, bridge } \\
\text { openings). }\end{array}$ \\
\hline TWRI 3-A5 & $\begin{array}{l}\text { Measurement of peak } \\
\text { discharge at dams by } \\
\text { indirect methods } \\
\text { (Hulsing, 1967) }\end{array}$ & $\begin{array}{l}\text { Flow over dams, } \\
\text { weirs, and road } \\
\text { embankments. }\end{array}$ \\
\hline
\end{tabular}


- Flood inundation mapping.-After a major flood, HWMs can be used to map the geographical coverage of flooded areas, depicting estimates of the areal extent and depth of flooding (Musser and others, 2016). Horizontal and vertical accuracy of the water surface is important; therefore, enough HWMs must be collected to determine the extent of the high-water inundation area of interest. A small, rural stream reach may require only 5 to $10 \mathrm{HWMs}$ to adequately define the extent of the flood water surface. An urban setting, however, with road embankments, storm sewers, culvert connections, and other urban structures, may require more HWMs to define the water-surface elevations within bounded or partially-bounded sections.

- Future uses such as bridge replacement or bridge design.-HWMs collected near hydraulic structures after major floods are important for future hydraulic modeling related to bridge replacement or bridge design. The documents listed in table 1 provide valuable information related to where HWMs should be collected relative to the type of structure and stream geometry and therefore, should be consulted for specific details. In general, HWMs should be collected in all four quadrants near the structure: upstream and downstream, right and left floodplains (fig. 1). 


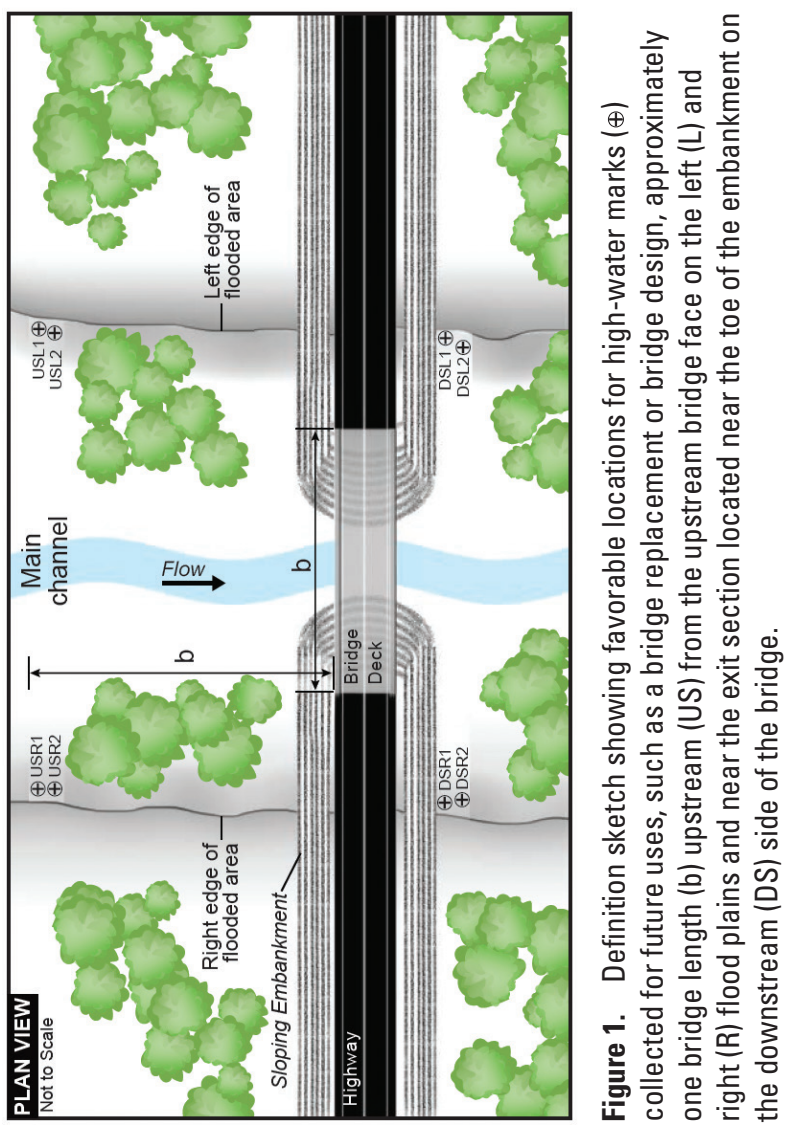


The HWMs for a bridge should be flagged about one bridge length (as measured from the left to the right edge of the bridge) upstream from the bridge face, which is typically considered to be out of the drawndown zone (Matthai, 1967). The downstream HWMs for a bridge should be collected near the outlet of the bridge, also referred to as the exit section. If the road was overtopped, HWMs should be collected along the road embankment far enough away from the bridge outlet so as to be in what would likely have been a pooled section. Typically collecting two or three reliable marks in each quadrant should be sufficient.

\section{Suggested Field Equipment for High-Water Mark Data Collection}

Field preparation includes arriving on site with the necessary tools and materials needed to properly complete an HWM investigation. Below is an extensive list of tools and items to consider in preparation for going to the field to identify and preserve HWM data. Not all these items will be needed in every situation, but they are provided to help field personnel think through the items that will likely be needed for their specific circumstances. 
- General

- Location map

- Topographic map

- Aerial photographs

- Bridge and road plans

- Pocket knife

- Backpack or other tool carrier

- Machete or lopping shears for reaching areas of dense brush

- Boat for reaching HWMs in swampy or still-inundated areas

- Ladder for unusual situations in which HWMs are higher than the field personnel can reach

\section{- Safety}

- First aid kit

- High-visibility safety vest for working around roadways or in the woods, especially during hunting season

- Personal flotation devices

- Wading boots, hip or chest waders, or snake boots (leggings)

- Flashlight 
- Hat

- Sunscreen

- Bug spray

- Drinking water and snacks

- Marking, flagging, and preliminary survey

- USGS plastic or metal tab markers

- Nails (duplex nails are easier to flag and remove)

- Hammer

- Flagging tape

- Wire marker flags

- Surveyor's hand level

- Steel rebar, wooden stakes, or both

- Permanent marker or grease pencil

- Tape measure, engineer's rule, or steel tape

- Carpenter's level

- Compass

- Rangefinder

- Two-way radios

\section{- Recording}

- Field notebook, field tablet device, or both 
- Cellphone or photography/video camera

- Surveying level, tripod, and rod

- Handheld Global Positioning System for coarse location of HWMs

- Special note sheets and forms

- Small dry-erase board and marker or clipboard with paper, for photograph documentation

- Total station instrument, tripod, rod, and prism for preliminary computations

If HWMs are being obtained for indirect discharge measurements, consult the relevant document in table 1 for a list of hydraulic related data to collect at the site.

\section{Types of High-Water Marks}

High-water marks provide evidence of the highest flood stage reached in an area. The types of HWMs in the flooded area will depend on the characteristics of the area. Brief descriptions of some of the HWMs field personnel might typically find are listed on the following pages. 
- Seed line.--Seeds or other fine material left as a line on things such as trees, bridge piers, and buildings (figs. $2 A, B$, and $C$ ) are called seed lines. Seed lines commonly provide some of the highest quality HWMs. Based on the density of the seeds and the consistency of the lines, a reasonable uncertainty value for these examples would be in the range of plus or minus ( \pm ) 0.01 to 0.02 foot (ft).

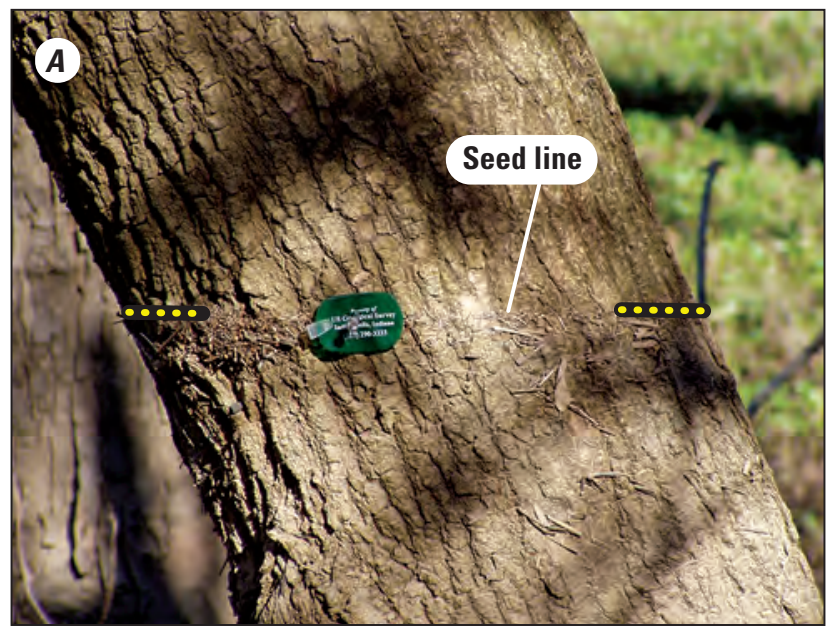

Figure 2. Well-defined seed lines on large tree trunks $(A, B$, and $C$ ). 

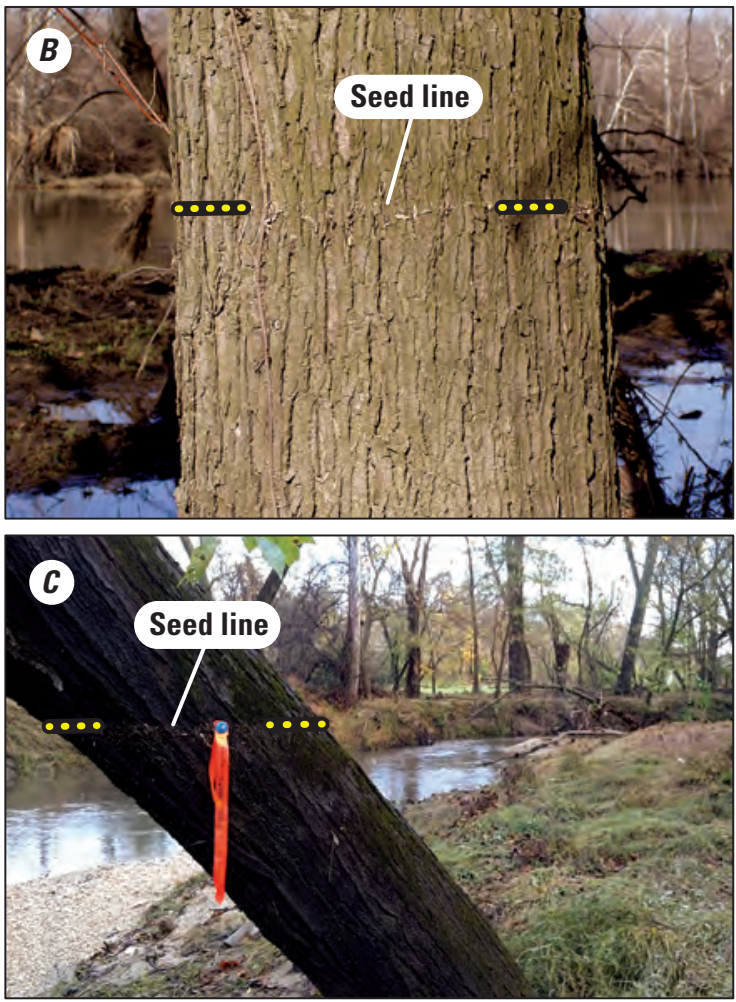

Figure 2. Well-defined seed lines on large tree trunks $(A, B$, and $C)$.-Continued 
- Mud or stain line.-A mud line, also called a stain line, is from sediment stain or general discoloration from water contact on things such as trees, bridge piers, and buildings (figs. $3 A, B$, and $C$ ). Most mud lines on natural surfaces (such as trees, shrubs, and grasses) are easier to see from a distance. A reasonable uncertainty value for figure $3 A$ could be $\pm 0.2 \mathrm{ft}$. For figure $3 B$, the mud line is consistent and pretty well matched by the line on the right side of the wooden steps; thus, an uncertainty of $\pm 0.05 \mathrm{ft}$ would be reasonable. For figure $3 C$, the mud line is straight and consistent all along the windows; thus, an uncertainty of $\pm 0.01 \mathrm{ft}$ would be reasonable.

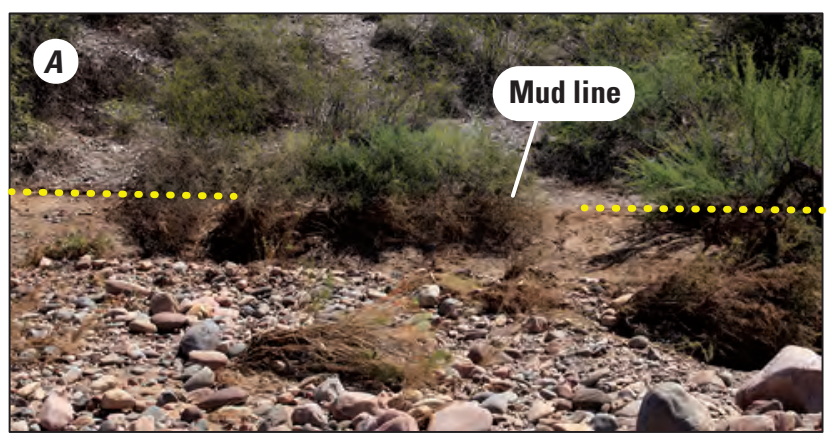

Figure 3. Examples of mud lines. $A$, mud line visible from a distance on desert shrubs; $B$, inside a previously flooded structure; and $C$, on the interior side of a glass wall. 

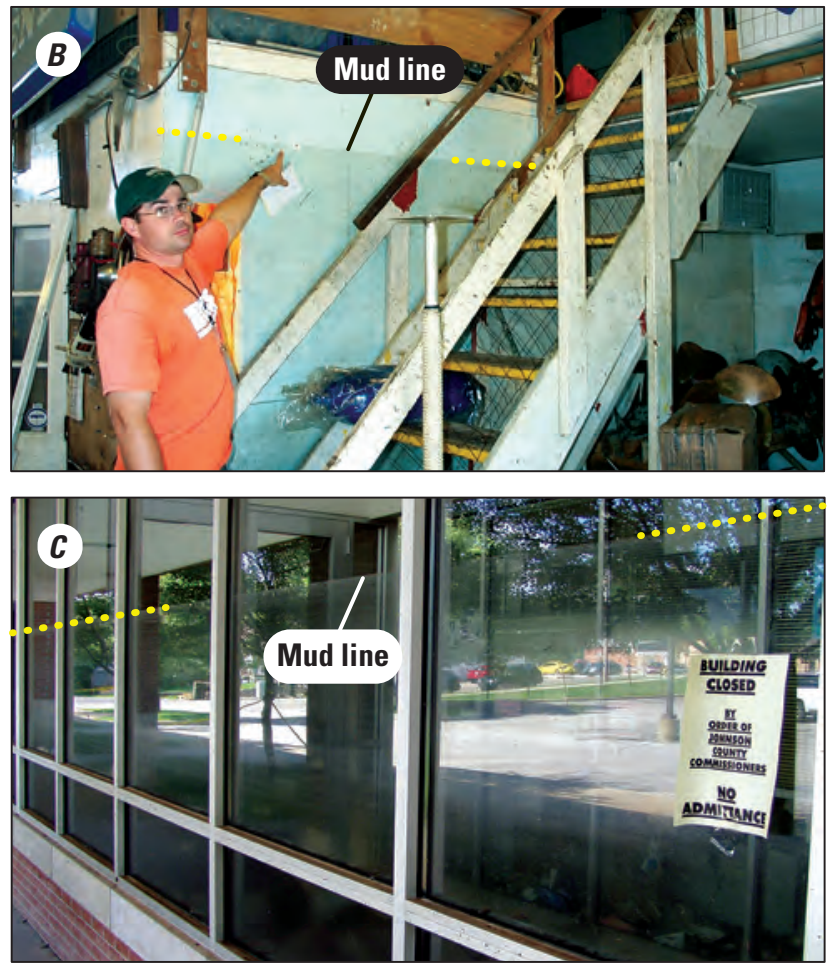

Figure 3. Examples of mud lines. $A$, mud line visible from a distance on desert shrubs; $B$, inside a previously flooded structure; and $C$, on the interior side of a glass wall.-Continued. 
- Debris or drift line.-Sticks, trash, and other coarse material left on the ground at the edge of the water (figs. $4 A$ and $B$ ) create debris lines, also called drift lines. Generally, debris lines are not as reliable as seed or mud lines because of the coarser texture and tendency to sag as the water recedes. A reasonable uncertainty for the debris lines shown in figures $4 A$ and $4 B$ would be approximately \pm 0.1 to $0.15 \mathrm{ft}$. The curves in the debris line in figure $3 A$ are likely from ground-slope elevation differences.

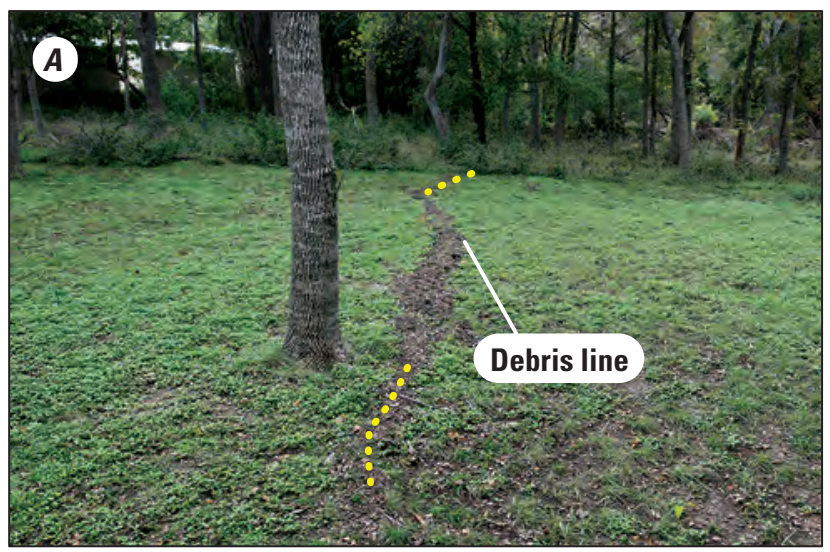

Figure 4. Examples of debris lines. $A$, debris line formed on grassy overbanks; and $B$, a grassy highway embankment. 


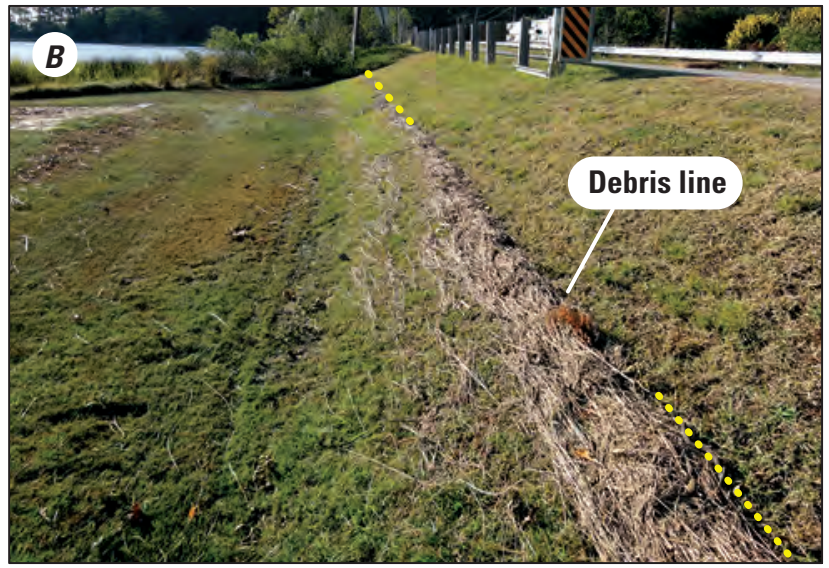

Figure 4. Examples of debris lines. $A$, debris line formed on grassy overbanks; and $B$, a grassy highway embankment.Continued

- Debris snag or trash line.-Debris snags, also called trash lines, are caused by coarse debris or trash collecting on obstructions, such as a structure, poles, fences, guy wires, trees, boulders, or bushes, in the water (fig. 5). For the debris line on the back of the fence in figure 5 , a reasonable uncertainty for an HWM might be about $\pm 0.2 \mathrm{ft}$, which is half the distance between the highest row of wire junctions that holds debris and the next highest row of junctions 
holding no debris. Debris snags on small trees and bushes tend to be less reliable because the tree or bush can be bent down by the force of the water when the debris collects and then stand back up when the water recedes (figs. $6 A$ and $B$ ).

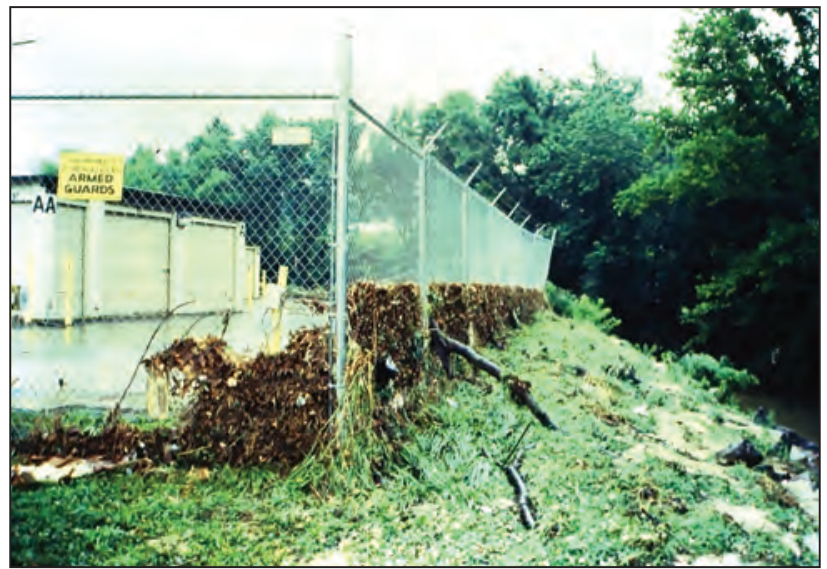

Figure 5. A line of debris collected along a chain-link fence. 


\section{A. Standing shrub}

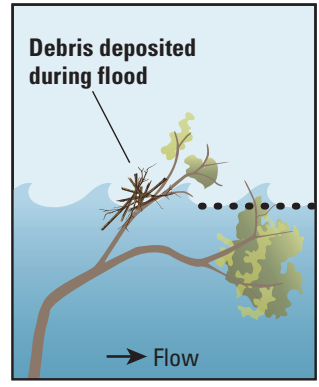

During flood

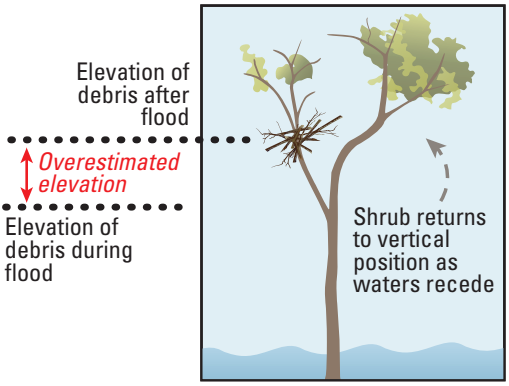

After flood

\section{B. Hanging branch}

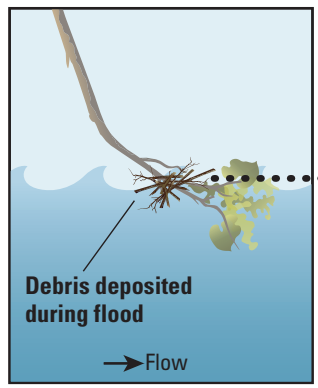

During flood
Elevation of debris during flood

$\uparrow$ Underestimated elevation

Elevation of debris after flood

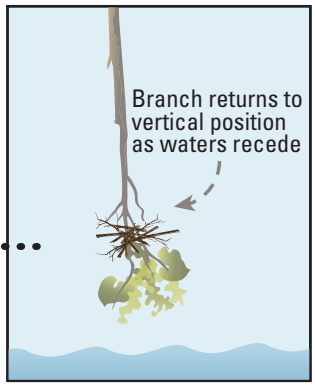

After flood

Figure 6. Diagrams illustrating how debris is deposited. $A$, on bendable shrubs; or $B$, on hanging branches during a flood can result in misleading high-water marks when the shrub or branch returns to its original position after floodwaters recede. Tree illustrations modified from Kraeer and others (2015). 
- Cut line.-A cut line is a line typically caused by rapid water eroding the stream bank at the water's edge (fig. 7). As noted by Koenig and others (2016), a reasonable uncertainty for the cut line shown in figure 7 might be $\pm 0.3 \mathrm{ft}$, assuming that range would account for potential slumping.

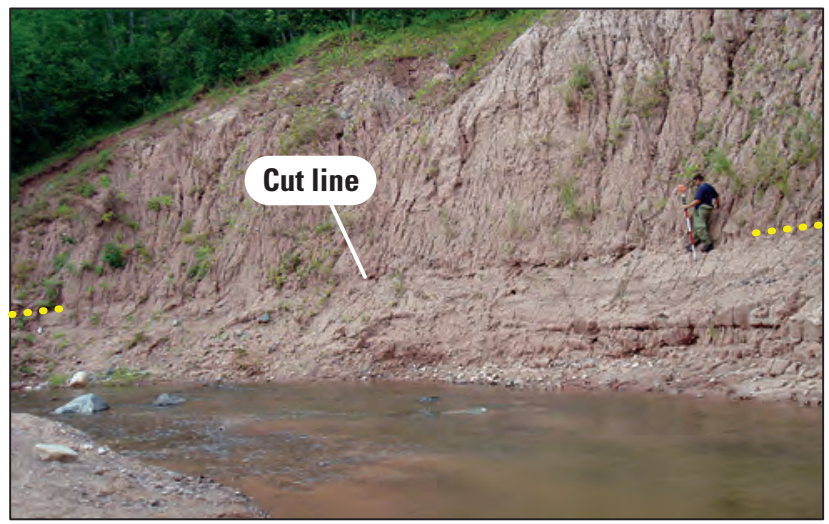

Figure 7. Preparing to survey a cut line in a sand/clay bluff.

- Wash line.-A wash line is a line on a bank indicating the removal of loose material from the top of the ground surface, revealing bare rock or a "cleaner" look than the adjacent nonflooded soil (figs. $8 A$ and $B$ ). The wash line in figure $8 B$ will tend 

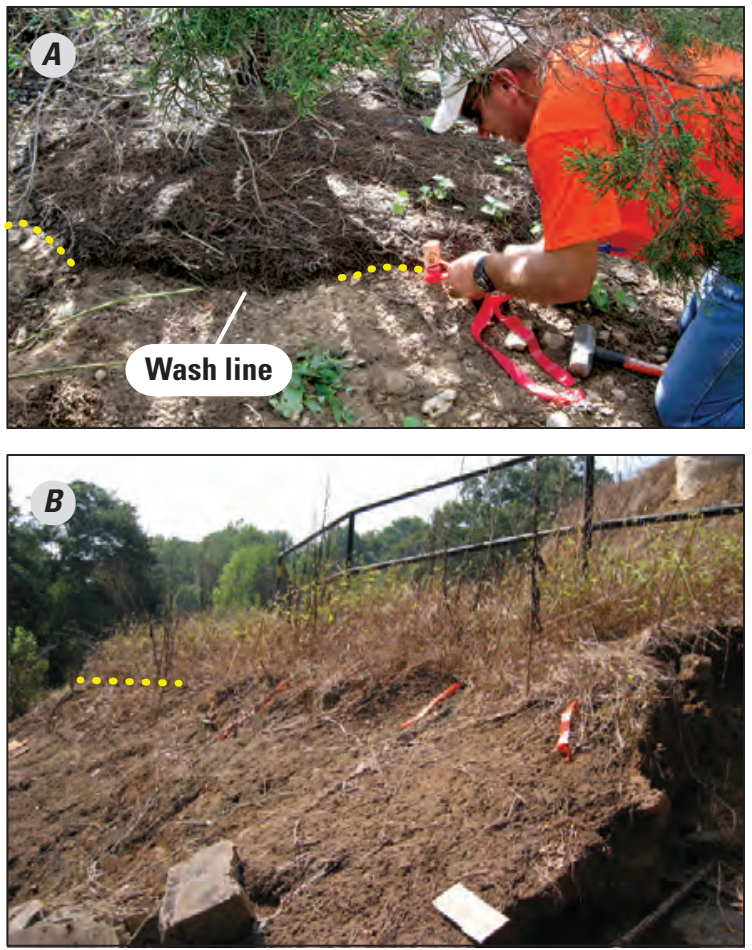

Figure 8. Examples of flagging a wash line. $A, A$ wash line that was created when floodwaters removed a thick bed of needles revealing the soil underneath; and $B$, at the edge of the grassy area. 
to have more uncertainty because of the overlapping vegetation and might be assigned an uncertainty of about $\pm 0.5 \mathrm{ft}$. For the wash line in figure $8 A$, a reasonable uncertainty might be between \pm 0.05 and $0.1 \mathrm{ft}$ because of the debris size, underlying substrate composition, and apparent continuity upstream and downstream.

\section{Rules of Thumb for Finding High-Water Marks}

The following are general rules of thumb when searching for HWMs.

- Because high-water marks can be highly perishable, time is of the essence. Once the flood has passed and it is safe to do so, visit the site(s) as soon as possible to flag the HWMs. The HWMs can be surveyed later.

- If possible, avoid swift water areas, which can cause varying amounts of pileup because the flow velocity causes marks to be higher on the upstream side of objects and lower on the downstream side. Lowvelocity areas, areas away from the main channel near the water's edge or close to the ground, tend to have better quality marks.

- Avoid HWMs on small bushes and trees in areas with substantial velocity (figs. $6 A$ and $B$ ). Vegetation may get bent down during the flood and stand back up after the flood, creating an artificially high-water surface. 
- Fences or window screens are usually good sources for HWMs.

- Building interiors will sometimes act as stilling wells. Field personnel should try to verify that the inside and outside levels have equalized.

- More HWMs are always better than fewer, especially if the marks are poor, the slope is steep, or the HWMs are being used in the determination of a flood profile.

\section{Location of High-Water Marks}

The purpose of the data will dictate the number and locations of flagged HWMs (see previous section titled "Purpose of High-Water Marks"). Below are some general guidelines.

- Label in a systematic fashion. The USGS references the left (L) and right (R) bank of a stream based on a person looking downstream (fig. 1).

- If applicable, reference the mark upstream (U) or downstream (D) from a "permanent" landmark such as a bridge (fig. 1).

- Locate marks on both banks and label as UL1, UL2, DR1, and DR2 (for sites upstream or downstream from a structure) or L1, L2, R1, and R2 (where no structure reference is necessary). The label also should include the uncertainty estimate, which is 
discussed later, for each mark such as UL1-0.05 ft or $\mathrm{R} 2-0.1 \mathrm{ft}$, indicating that mark UL1 had an uncertainty of $\pm 0.05 \mathrm{ft}$ and mark R2 had an uncertainty of $\pm 0.1 \mathrm{ft}$.

- Flag more HWMs than you think you will need. Remember, it is better to have them and not need them than to need them and not have them.

- Get HWMs through the reach of interest and a short distance upstream and downstream from the reach.

- Be aware of local effects, pile up, and drawdown. Typically, use top of seed lines and ground at landward edge of drift lines.

\section{Flagging and Documenting High-Water Marks}

Because HWMs should be flagged as quickly as possible after a flood, separate field crews will commonly flag and later survey the HWMs; therefore, field notes should provide sufficient details to allow HWM recovery by the survey crew. Suggestions for flagging and documenting HWMs are listed below.

- Typical markers include nails, stakes, brightly colored survey flagging tape, wire flags, USGS marking tabs, paint, permanent ink markers, and chiseled marks (figs. $9 A, B, C$, and $D$ ). 

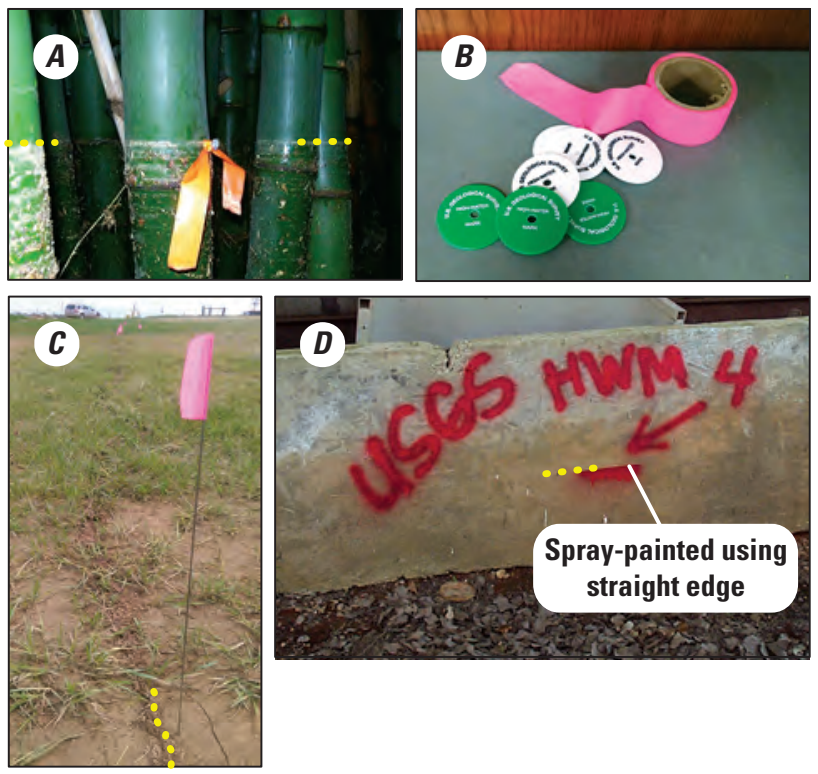

Figure 9. Examples of markers for recording high-water marks. $A$, a nail and brightly colored flagging tape used to mark seed lines on bamboo; $B$, flagging tape and U.S. Geological Survey marking tabs; $C$, a wire flag marking a debris line on the ground; and $D$, a spray-painted line (using a straight edge) making a precise high-water mark on a concrete divider. 
- The unique HWM identifier should be written on the mark indicator along with the uncertainty estimate (UL1 $\pm 0.1 \mathrm{ft}, \mathrm{DR} 2 \pm 0.05 \mathrm{ft}$, and so forth). Additional survey flagging should be used to help identify the general proximity of a mark to assist recovery efforts in thick vegetation during the survey phase.

- When applicable, field crews should obtain permission from landowners before placing permanent or semipermanent markings on private property. Otherwise, measure up or down to the HWM from metal or concrete points of reference, where available. Alternatively, drive a stake in the ground below the mark and measure to the top of the stake.

- Marks that are likely to be difficult to survey, such as those inside a previously flooded structure or on the opposite side of a tree from which the surveying is likely to be done, should be transferred to a more accessible location with the same elevation using a carpenter's level (fig. 10).

- Photographs should be taken of the marks. Date stamped digital photographs are ideal.

- Along with high-quality photographs, detailed notes should be taken to provide a record that can be useful for future reference. The form used and details included may be specific to a particular 

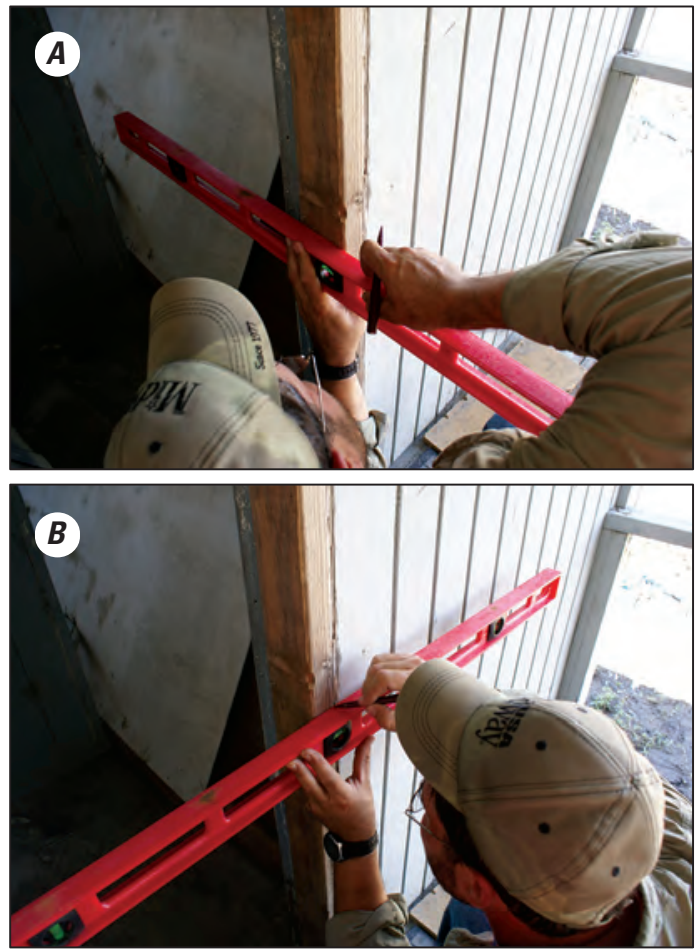

Figure 10. Field personnel using a carpenter's level to transfer high-water marks. $A$, from inside a structure; and $B$, to the outside to facilitate easier surveying of the mark. 
HWM investigation, but Koenig and others (2016) provides a USGS form that can be downloaded from https://doi.org/10.3133/tm3A24, printed, and copied for use in the field. At a minimum, field notes should include the following information:

- Type of mark (seed line, mud line, and so forth).

- Location of the mark (latitude and longitude, distance from one or more defined points).

- Uncertainty of the mark.

- Important miscellaneous notes such as landowner contact information, logistics, and safety information.

- Map/site sketch with HWM identifier and locations noted.

- Digital photograph numbers.

- Remember that after all HWMs have been surveyed, nails driven into tree trunks or stakes driven into the ground should be removed along with any flagging. Nails left in trees after the study may cause serious injury when those trees are cut. Partially exposed stakes may puncture vehicle tires or become a tripping hazard.

- If HWMs are in the woods, flag a point of entry into the woods and the path to the HWM. In addition, if 
the mark is on a tree, flag the tree on the side that faces the road so it can be easily identified.

\section{Evaluating High-Water Marks}

Assigning uncertainty is looking at each mark and asking: "What is the most likely range of water-surface elevations that could be described by this mark?" Such information helps all future users of the HWMs to infer the best water surface. Uncertainty may be very difficult to determine from a photograph; therefore, every HWM should be assigned an uncertainty by the field personnel who flagged it. A well-defined seed line is likely to have a smaller uncertainty, such as within $\pm 0.05 \mathrm{ft}$. On the other hand, a cut line such as the one shown in figure 7 might be assigned an uncertainty value of $\pm 0.3 \mathrm{ft}$. A common USGS shorthand standard for uncertainty is listed in table 2. Field personnel choosing to use uncertainty shorthand should ensure that abbreviations written on flagging represent the same numeric values shown in table 2; for example, a mark labeled UL1-0.05 ft (preferred) could be labeled as UL1E. 
Table 2. High-water mark uncertainty shorthand (modified from Rydlund and Densmore, 2012).

\section{Amount of vertical uncertainty}

Within \pm 0.05 foot

Within \pm 0.10 foot

Within \pm 0.20 foot

Within \pm 0.40 foot

More than \pm 0.40 foot

High-water mark defines the minimum height of the peak, but peak may have been higher to an unknown extent.

\section{Shorthand}

Excellent (E)

Good (G)

Fair (F)

Poor (P)

Very poor (V)

At least this high

(ALTH) 


\section{Best Practices-Developing an Eye for Finding High-Water Marks and Avoiding Pitfalls}

Experienced field personnel agree on several tips for improving the likelihood of identifying high-quality marks.

1. Safety first.-Although many HWMs are surveyed after dangerous floods have receded, floods and storms that create HWMs may leave behind unstable structures, broken debris with sharp edges, damaged power lines, and unstable roads and footpaths. Field personnel should always beware of lingering dangers associated with the flood, even after the event has passed. Floods often transport hazardous chemicals or fouled waters from urban or farm-related sewage systems, and polluted water may linger in streams or nearby pools in the landscape after the flood has receded. Careful attention to odors, proper handwashing, and cleaning of equipment will guard against risk of illness in this type of fieldwork. Floods also have a tendency to drive wildlife upward from the flood plain to whatever structures or shrubbery are available to escape the rising waters. A debris pile shown in figure 11 shares a tree with a creature that may not welcome an unobservant person. A variety of hazards that are present during and after a flood are shown in figure 12 . 


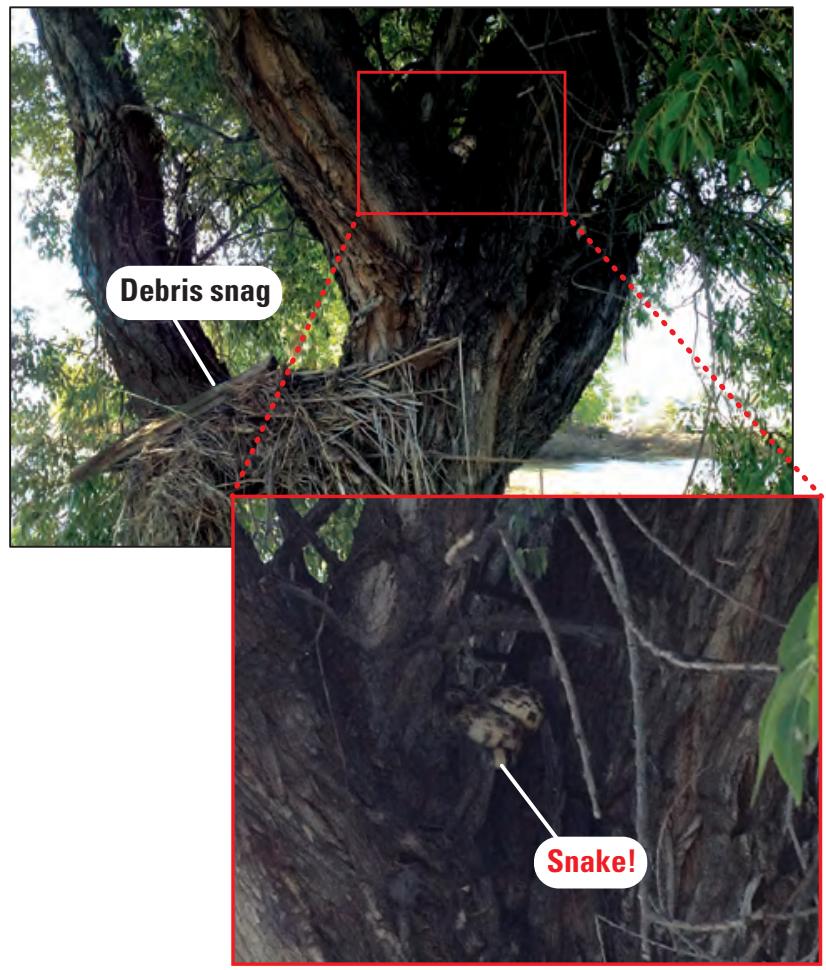

Figure 11. A debris pile in a tree with a snake napping in an upper branch. 


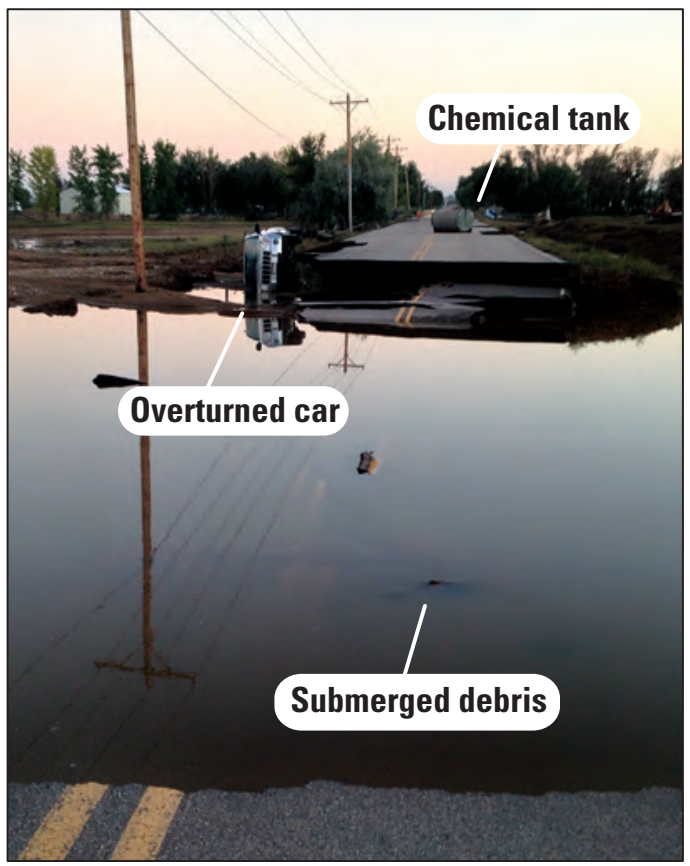

Figure 12. A road washout just downstream from a livestock farm on St. Vrain Creek, Colorado. This photograph shows a few hazards associated with flooding, which include the chemical tank that has floated away from its mooring and a vehicle that is overturned; the driver likely failed to see the washed-out road because of high floodwaters. 
2. Respond quickly.-Most HWMs are perishable and fragile and are likely to be disturbed, degraded, or destroyed by natural forces or cleanup efforts. The most important success factor when documenting HWMs is to identify the marks before they change or disappear.

3. Look up.-As floodwaters recede, secondary events may form multiple HWMs below the highest mark (fig. 13). Sometimes, a lower, secondary mark is

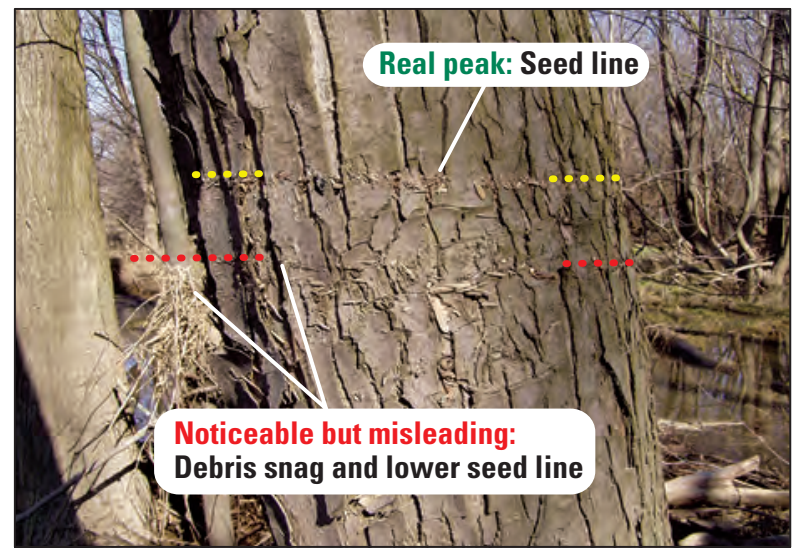

Figure 13. A debris snag and two seed lines. The debris snag on the left side of the trunk may have led the field personnel to mark the lower seed line, but a quick glance upward reveals the true peak high-water mark. 
more obvious or is the first mark noticed, especially in coastal areas. To improve the likelihood that the peak mark has been identified, field personnel should develop a habit of thoroughly checking above each HWM.

4. Stand back.-A wider view may show patterns that are invisible up close, which is especially true with mud lines in low brush and foliage. Observe the lines from a distance to place localized slumps in wash lines and debris lines in context. If available, look through a surveyor's hand level from the elevation of a trusted HWM to aid in identifying or verifying other HWMs. Tie temporary flagging to preliminary marks to help visualize the high-water line when stepping back. In addition, check structures for evidence of shifting or settling that may have been caused by the floodwaters (fig. 14). Shifting increases the uncertainty of the HWM elevation because it may be impossible to determine the position of the structure when the marks were made.

5. Visualize the flood.-Observe the channel and imagine the water at the peak stage. Try to visualize the characteristics of the water that created the observed HWMs. For overbank flows, try to pinpoint where the water's edge met the ground and look for verifying HWMs; flows near the water's edge tend to be more 


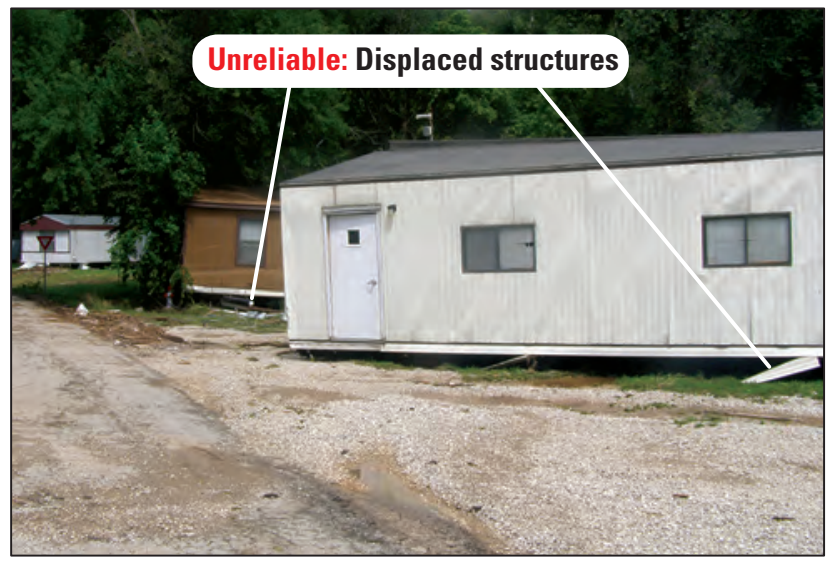

Figure 14. Structures with high-water marks that have likely moved during the flood, making peak water surface uncertain.

tranquil and leave better marks. In confined channels, such as deep canyon streams, look for reaches that are as uniform as possible and locate areas where floodwaters were completely confined to the main channel. Beware of roadways that may have interfered with flow or provided side channels with false HWMs. Additionally, note obstructions that could have locally impeded flow and channel bends that could result in a superelevated water surface. 
6. Hunt for hidden clues. - Look for still-water locations such as ineffective flow areas or the interiors of enclosures and structures. These areas often have the best HWMs because they collect finer debris in thin lines. A fair mark on the outside of a building can correspond to an excellent mark inside an enclosure, as shown in figure 15; however, recognize that structures with weak hydraulic or atmospheric connections may fill too slowly to reflect the outside peak water surface.

A. Enclosed areas also can preserve marks from weather and other disturbances. Pay attention to small enclosures, such as utility boxes. Even if rain washes out most HWMs before a field crew arrives, suitable marks may still exist if they are shielded overhead by tree canopies, bridge decks, rooftops, and other structures.

B. Although larger debris piles may not make high-quality HWMs, the piles may lead field personnel to better HWMs nearby, or the piles may create slack water conditions along a bank where good seed lines may form. 

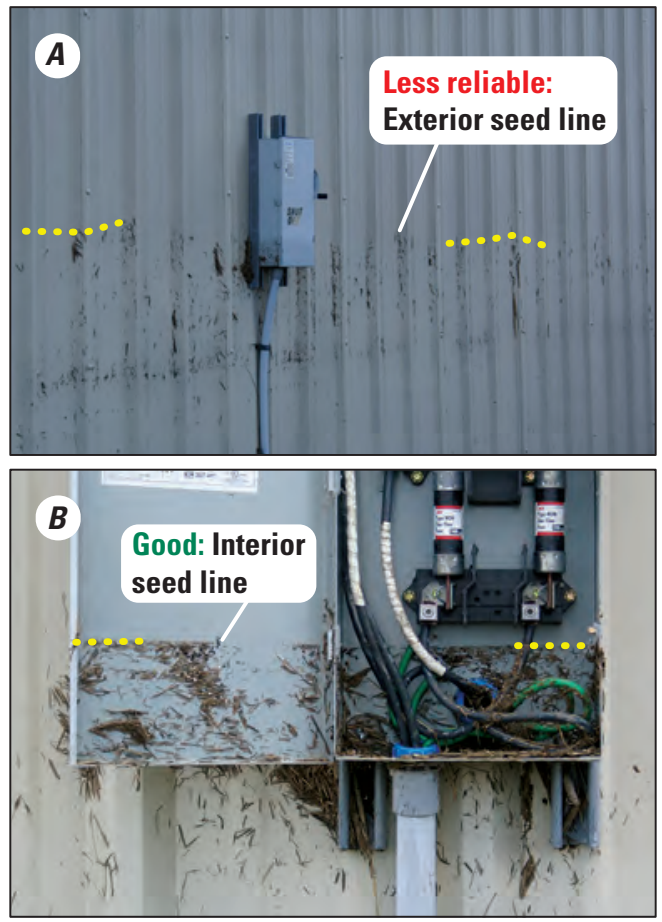

Figure 15. Seed lines. $A$, formed on the outside structure and $B$, inside an enclosure attached to the structure. Although the exterior seed line was not a high-quality high-water mark, it led the field personnel to the excellent seed line inside the utility box. 
7. Think ahead.-Always hunt for HWMs with the end purpose in mind. Knowing the application of the data is essential to collecting the necessary quantity of marks from the most useful locations and ensuring sufficient water-surface information for peak verification, indirect streamflow measurement, flood inundation studies, model calibration, or other applications that will follow. Field personnel searching for HWMs for indirect measurements or coastal surge campaigns should be well-versed in those methods, or they should search for HWMs under the guidance of experienced field personnel. When field personnel are identifying HWMs for indirect streamflow measurements, an immediate partial survey of those marks will help to identify structures or reaches with insufficient fall (slope) for reliable computations, which in the case of width contraction and slope-area method indirects is less than $0.50 \mathrm{ft}$ for the defined reach being analyzed (Matthai, 1967; Dalrymple and Benson, 1967). These partial surveys may save considerable time by avoiding unworkable full geometric surveys of reaches that have insufficient fall or other unfavorable conditions that prevent a good measurement. A photograph showing a plot of HWMs that was created in the field before beginning a full cross-section survey for an indirect streamflow measurement is shown in figure 16. If time does not 


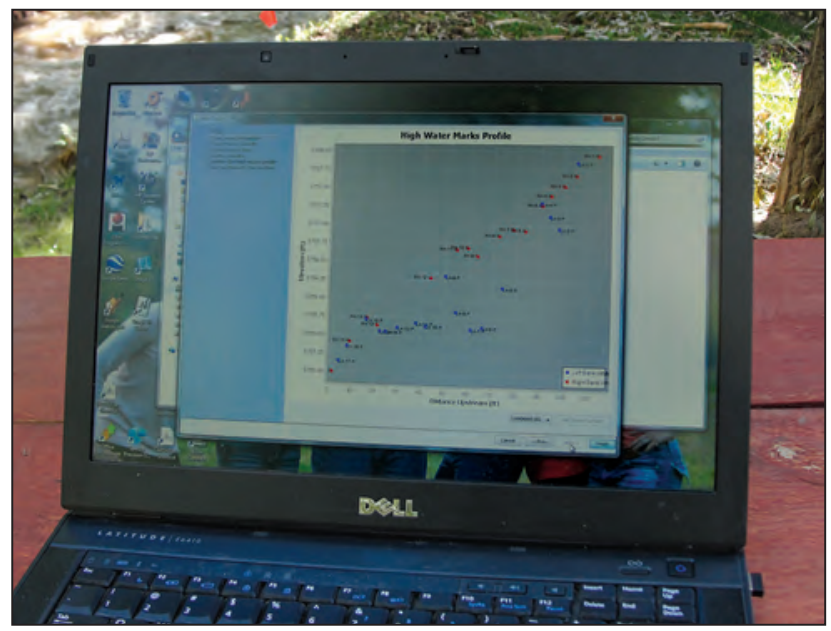

Figure 16. A laptop computer showing a plot of high-water marks created in the field.

allow for a full cross-section survey, an immediate HWM survey may be needed nonetheless to preserve the water-surface elevation data, especially in urban areas where cleanup crews may destroy HWMs or markers.

8. When in doubt, collect more data.-Time is rarely wasted by collecting a large number of HWMs. Collecting multiple marks to verify the peak stage at a 
streamgage adds more confidence to the verification than collecting only one mark and requires little additional effort. Similarly, the changes in water-surface slope of a steep mountain stream with 20 or 30 marks per hundred feet will be much easier to assess than a stream with only a few marks. Indirect streamflow measurements on mild slopes also benefit from the improved accuracy of more marks, especially when marks have greater uncertainty. An outlier among 10 marks is much easier to discard than an outlier among 5 marks. If the best site is predominated by marks with high uncertainty, do not attempt to adjust or correct HWMs to fit an assumed water surface (Benson and Dalrymple, 1967). Instead, improve the estimated peak water surface by collecting additional marks, recording the vertical uncertainties, and letting the data tell the story.

\section{References Cited}

Benson, M.A., and Dalrymple, Tate, 1967, General field and office procedures for indirect discharge measurements: U.S. Geological Survey Techniques of Water-Resources Investigations, book 3, chap. Al, 30 p. (Reprinted 1984.) [Also available at https://pubs.er.usgs.gov/publication/twri03A1.] 
Bodhaine, G.L., 1968, Measurement of peak discharge at culverts by indirect methods: U.S. Geological Survey Techniques of Water-Resources Investigations, book 3, chap. A3, 60 p. (Reprinted 1982.) [Also available at https://pubs.usgs.gov/twri/twri3-a3/.]

Dalrymple, Tate, and Benson, M.A., 1967, Measurement of peak discharge by the slope-area method: U.S. Geological Survey Techniques of Water-Resources Investigations, book 3, chap. A2, 12 p. (Reprinted 1989.) [Also available at http://pubs.usgs.gov/twri/twri3-a2/.]

Hulsing, Harry, 1967, Measurement of peak discharge at dams by indirect methods: U.S. Geological Survey Techniques of Water-Resources Investigations, book 3, chap. A5, 29 p. (Reprinted 1968.) [Also available at https://pubs.usgs.gov/twri/twri3-a5/.]

Koenig, T.A., Bruce, J.L., O’Connor, J.E., McGee, B.D., Holmes, R.R., Jr., Hollins, Ryan, Forbes, B.T., Kohn, M.S., Schellekens, M.F., Martin, Z.W., and Peppler, M.C., 2016, Identifying and preserving high-water mark data: U.S. Geological Survey Techniques and Methods, book 3, chap. A24, 47 p. [Also available at https://doi.org/10.3133/tm3A24]

Kraeer, Kim; Van Essen-Fishman, Lucy; and Saxby, Tracey, 2015, Illustrations from the IAN Image and Video Library: Integration and Application Network, University of Maryland Center for Environmental Science, accessed January 4, 2016, at http://ian.umces.edu/imagelibrary/. 
Matthai, H.F., 1967, Measurement of peak discharge at width contractions by indirect methods: U.S. Geological Survey Techniques of Water-Resources Investigations, book 3, chap. A4, 44 p. (Reprinted 1976) [Also available at https://pubs.usgs.gov/twri/twri3-a4/.]

Musser, J.W., Watson, K.M., Painter, J.A., and Gotvald, A.J., 2016, Flood-inundation maps of selected areas affected by the flood of October 2015 in central and coastal South Carolina: U.S. Geological Survey Open-File Report 2016-1019, 81 p. [Also available at https://pubs.er.usgs.gov/publication/ofr20161019.]

Rydlund, P.H., Jr., and Densmore, B.K., 2012, Methods of practice and guidelines for using survey-grade global navigation satellite systems (GNSS) to establish vertical datum in the United States Geological Survey: U.S. Geological Survey Techniques and Methods, book 11, chap. D1, 102 p. with appendixes. [Also available at https://pubs.usgs.gov/tm/11d1/.]

U.S. Geological Survey, 2017, Documenting the deluge-USGS teams search South Louisiana to determine recent flood's highest peak: U.S. Geological Survey news web page, accessed April 3, 2017, at https://www.usgs.gov/news/documenting-deluge-usgsteams-search-south-louisiana-determine-recent-flood-shighest-peak. 


\section{Appendix 1. High-Water Mark Examples}

The following photographs were obtained from various U.S. Geological Survey high-water mark field investigations and are provided as an example of some of the types of marks discussed in this field manual along with an assigned uncertainty rating. Most of the photographs are from floods in the Southeastern United States. General comments about the logic for the assigned uncertainty value also are included in this report. The yellow lines on the photographs are included to clearly indicate the location of the high-water mark.

\section{Seed Lines}

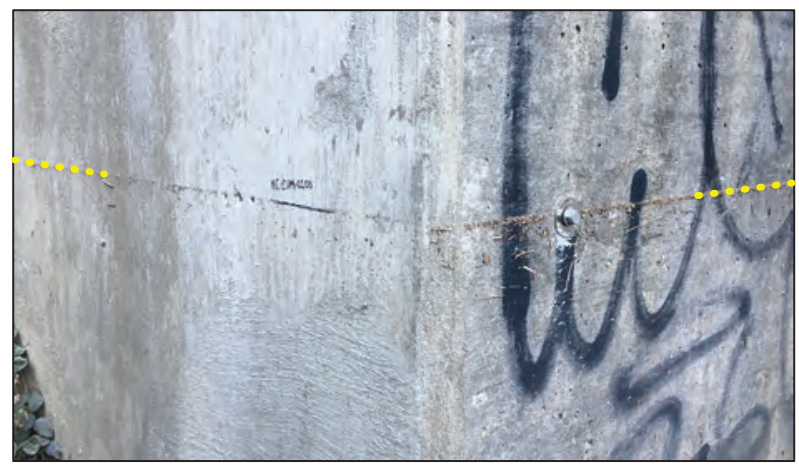

Figure 1-1. Seed line with uncertainty of \pm 0.01 foot. The line is on an outside structure (good hydraulic connectivity) and is consistent and straight with no seeds above the line. 


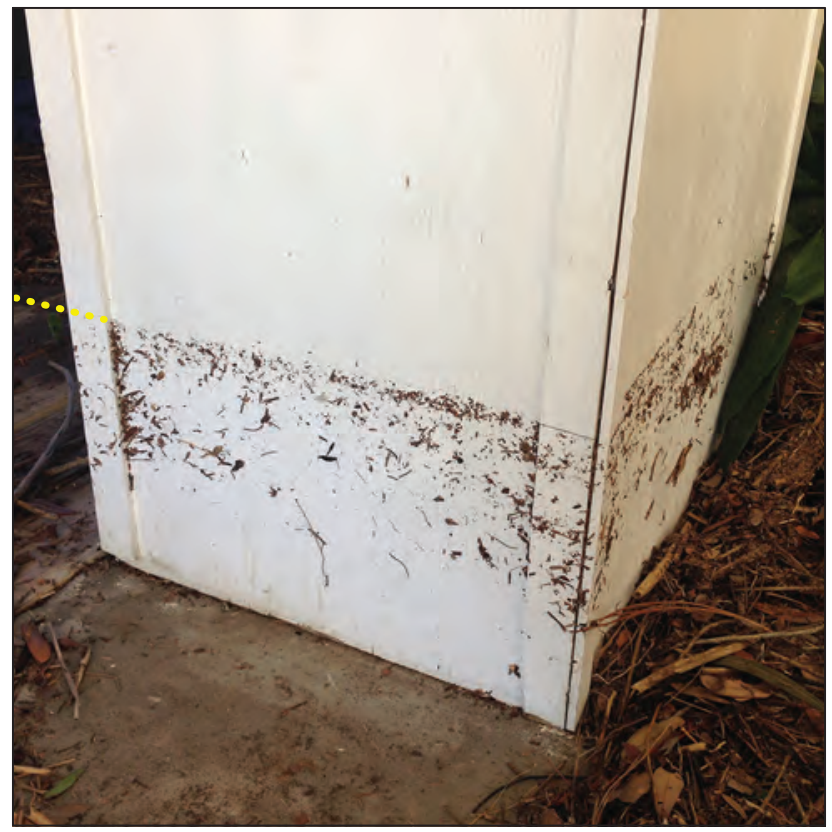

Figure 1-2. Seed line with uncertainty of \pm 0.02 foot. The seed line is on an outside structure, consistent and straight with nothing substantial above the line. 


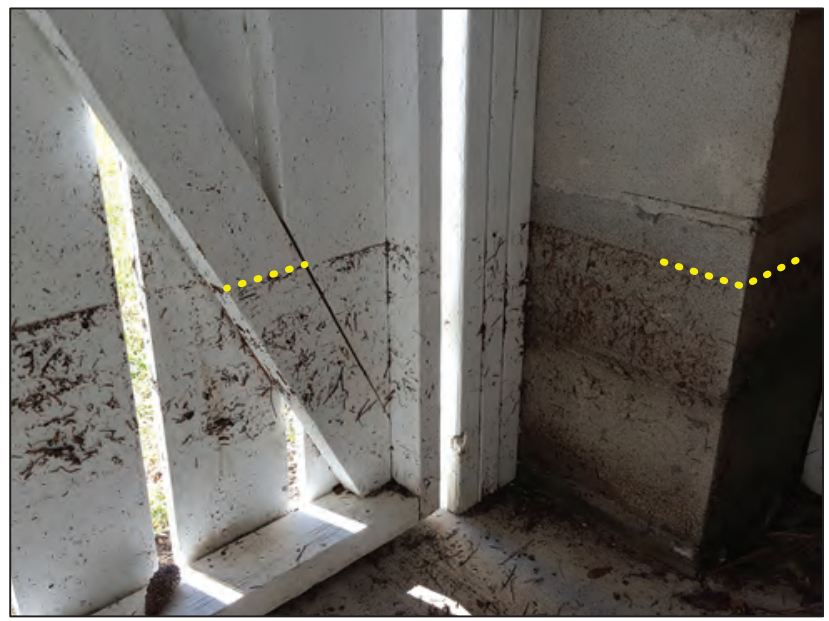

Figure 1-3. Seed line with uncertainty of \pm 0.02 foot. The seed line is consistent and straight. Just based on the white gate-like structure, a higher uncertainty might be assigned because of the debris scattering above the main mark. However, the debris scattering is not evident on the concrete blocks and thus may have been from material washing down from above the seed line or some other source of scatter. 


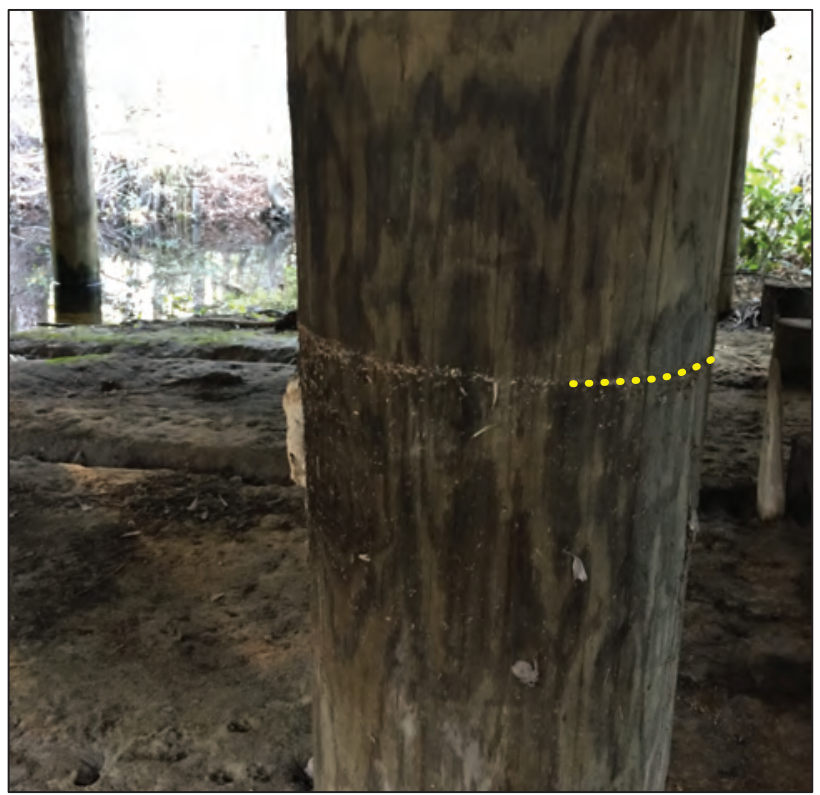

Figure 1-4. Seed line with uncertainty of \pm 0.02 foot. The seed line is straight with no debris above it. This uncertainty estimate assumes that the seed line is consistent on the other side of the pole, indicating no substantial issue with runup from swift-water conditions. 


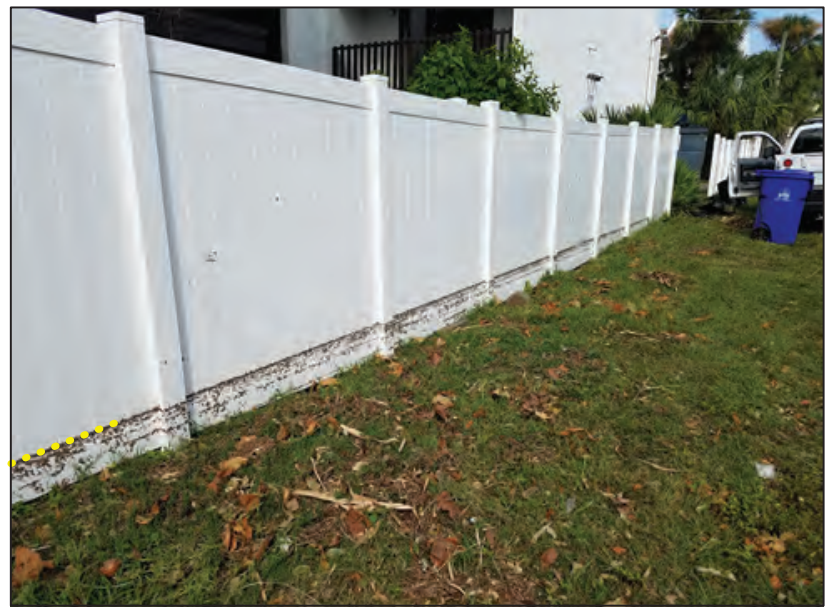

Figure 1-5. Seed line with uncertainty of \pm 0.02 foot. The seed line is consistent and straight. 


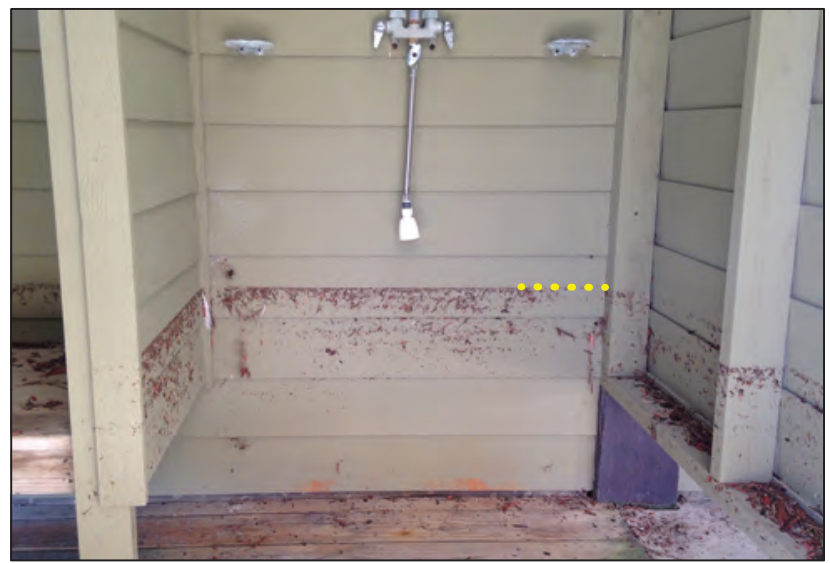

Figure 1-6. Seed line with uncertainty of \pm 0.02 foot. The seed line is well-defined and is located in an outside bath shower. 


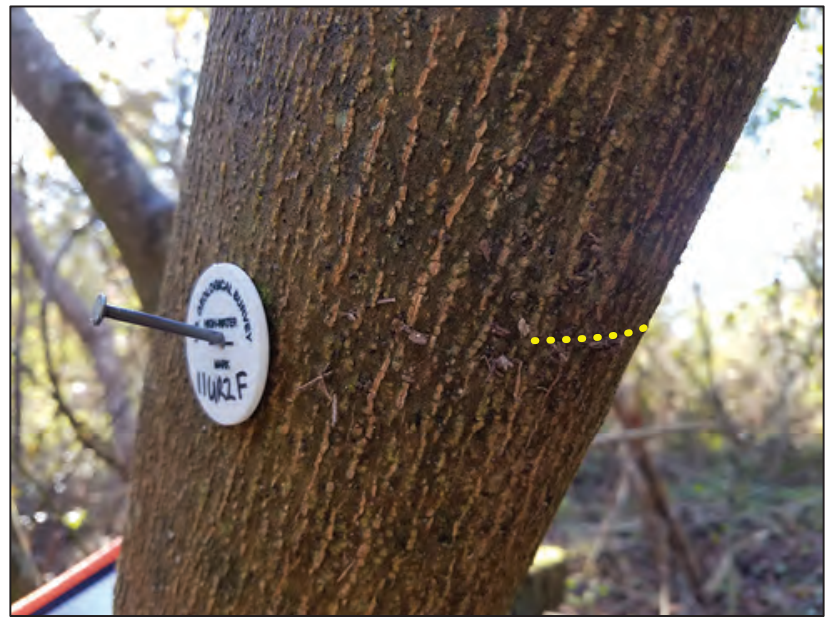

Figure 1-7. Seed line with uncertainty of \pm 0.05 foot. Overall, there is a clear pattern of seeds on the bottom side of this leaning tree, but the scatter in the seed debris may indicate wave action. 


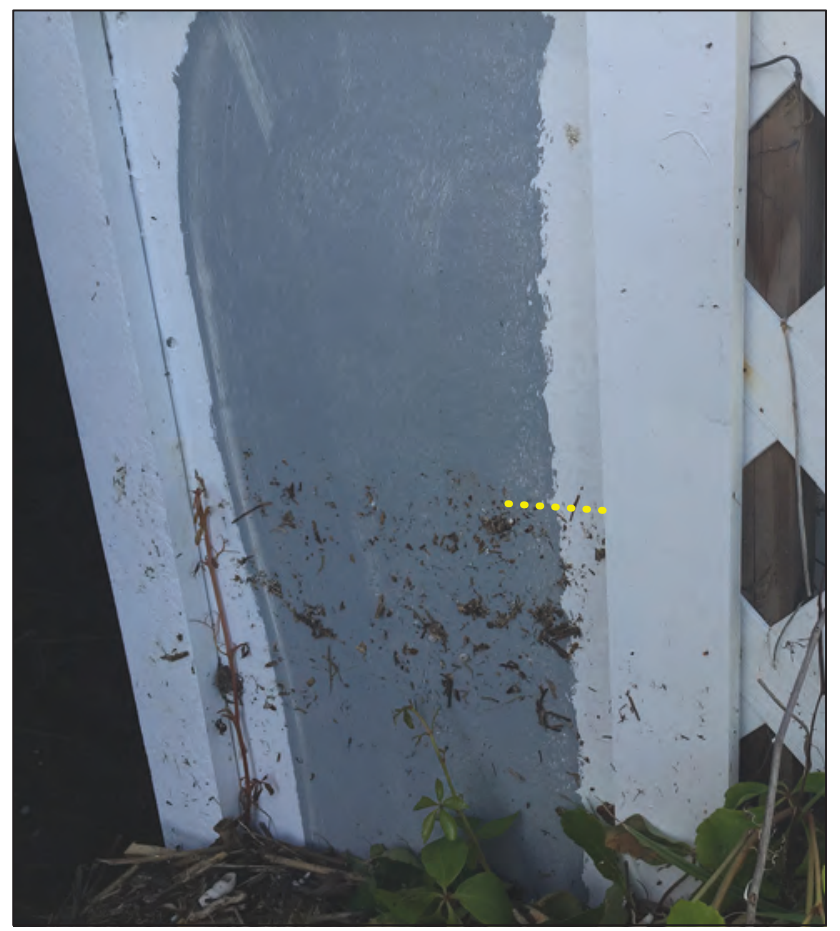

Figure 1-8. Seed line with uncertainty of \pm 0.05 foot based on the yellow line. There is a lot of scatter in the debris, possibly from wave action. No seed line at the same elevation is shown on the trellis. 


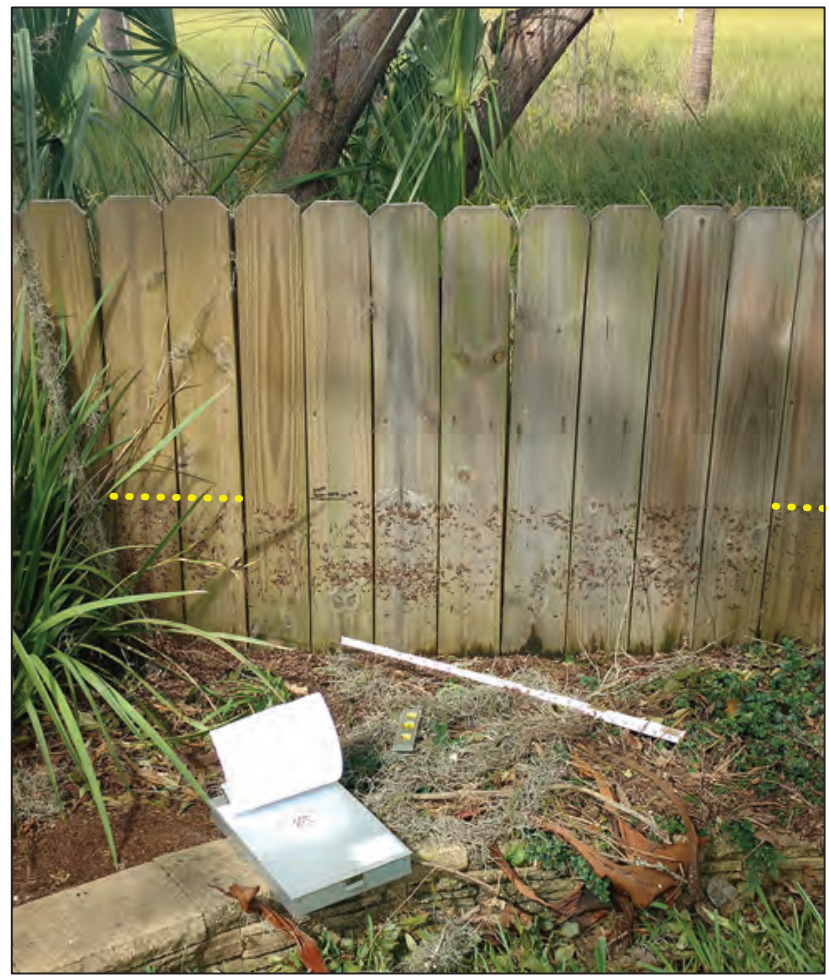

Figure 1-9. Seed line with uncertainty of \pm 0.05 foot. There is little to no debris above the seed line, but there is a little variation in the seed line. 


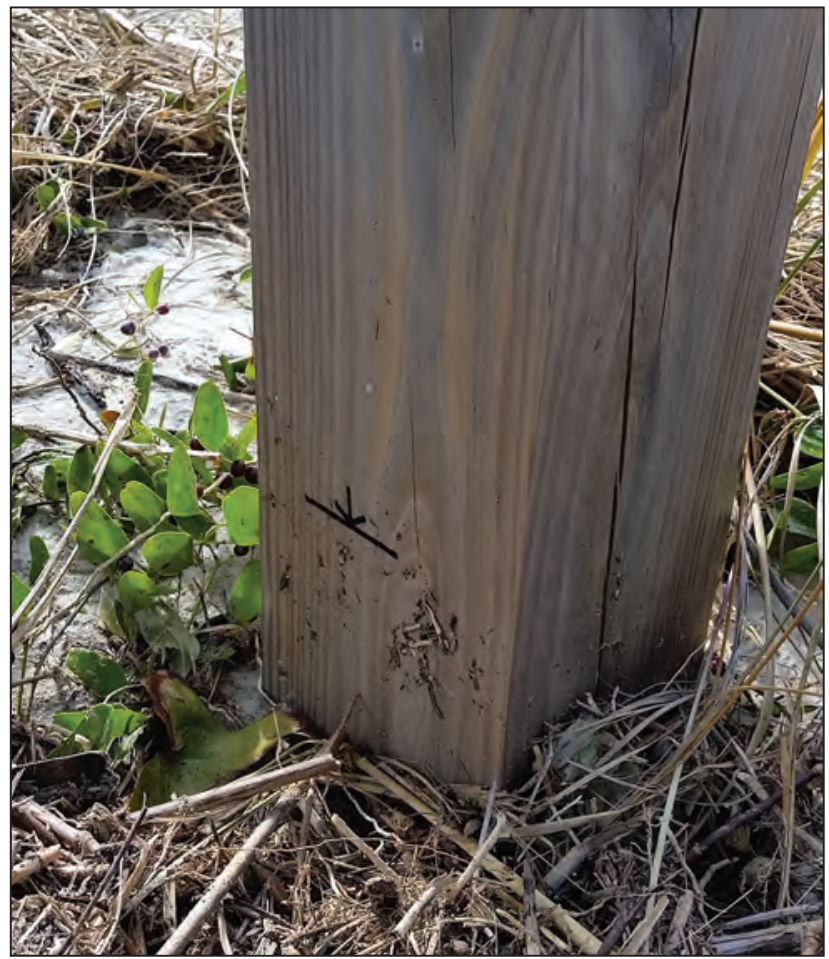

Figure 1-10. Seed line with uncertainty of \pm 0.2 foot. There is not a consistent seed line on the two sides of the post that are shown, and there is some scatter at the location where the seed line was noted by the black arrow. 


\section{Mud Lines}

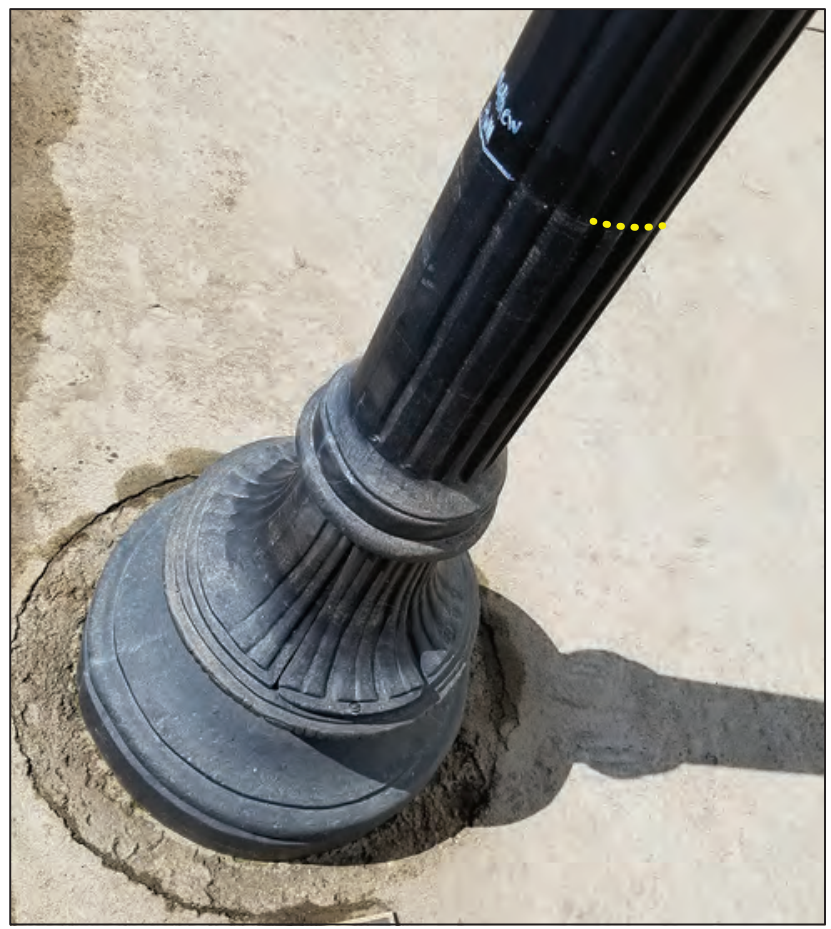

Figure 1-11. Mud line with uncertainty of \pm 0.02 foot. The mud line (blue marking on the pole) appears to be consistent and well-defined. 


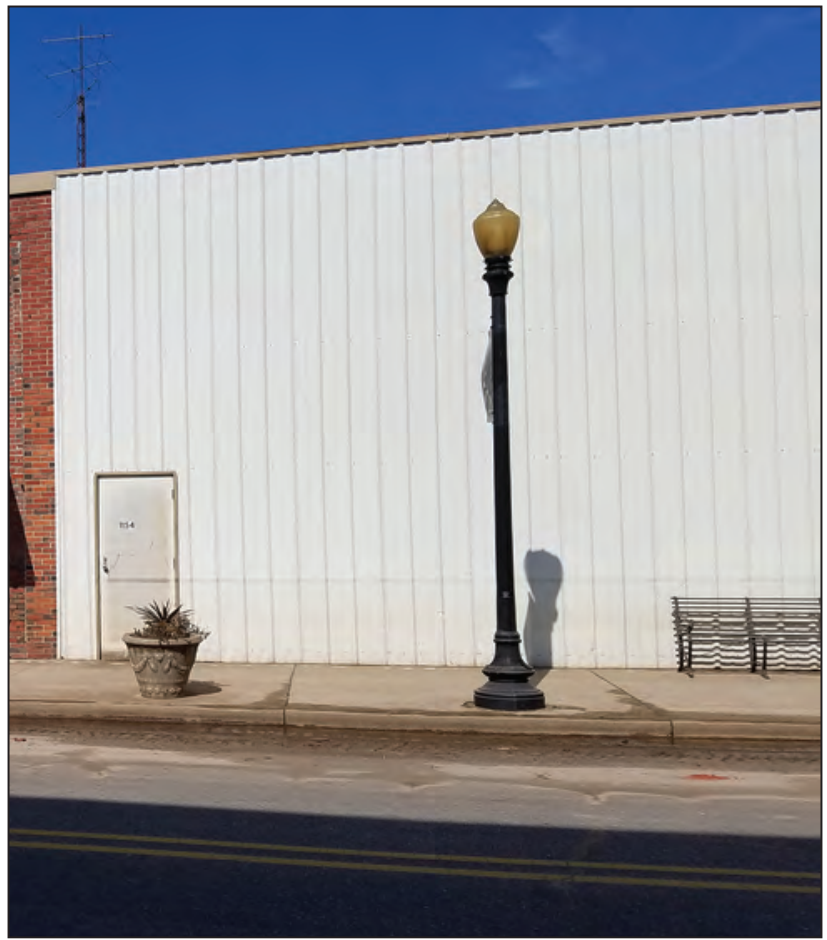

Figure 1-12. Mud line with uncertainty of \pm 0.02 foot. Although the photograph of the mud line was taken from a distance, there is a clear straight line on the white metal panels on the building. The line is just above the park bench. 


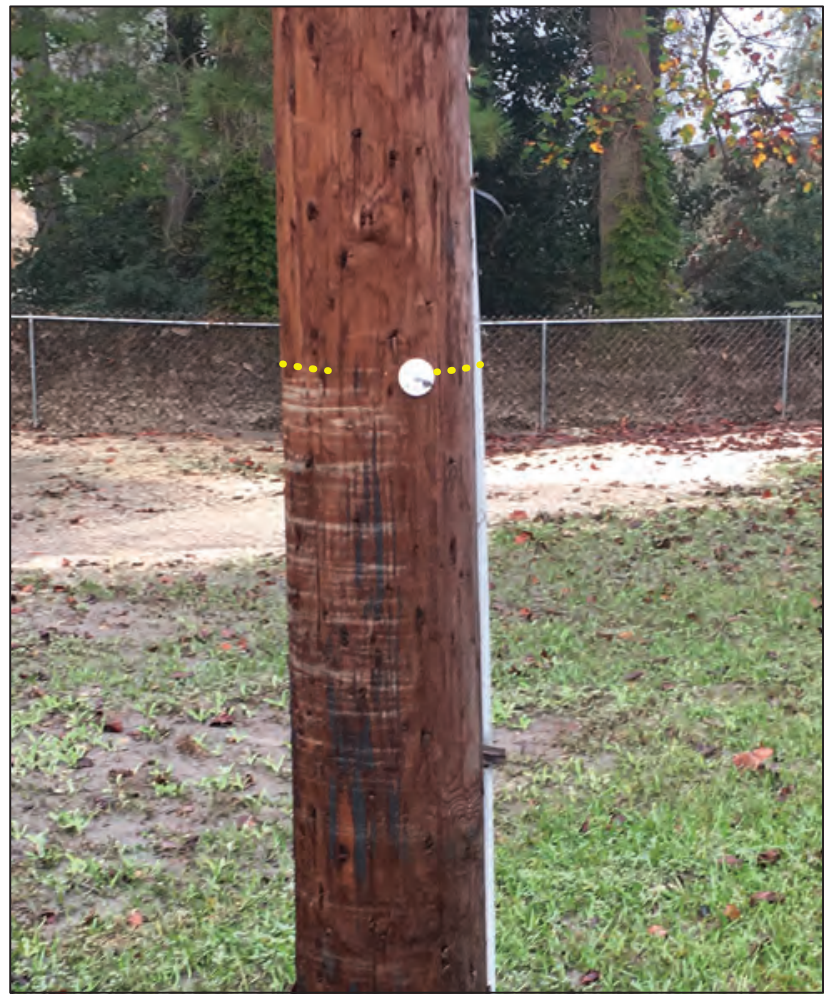

Figure 1-13. Mud line with uncertainty of \pm 0.05 foot. No stain shown above the nail (at the yellow line) but that mud line is faint and could have been disturbed by additional rain after the flood. 


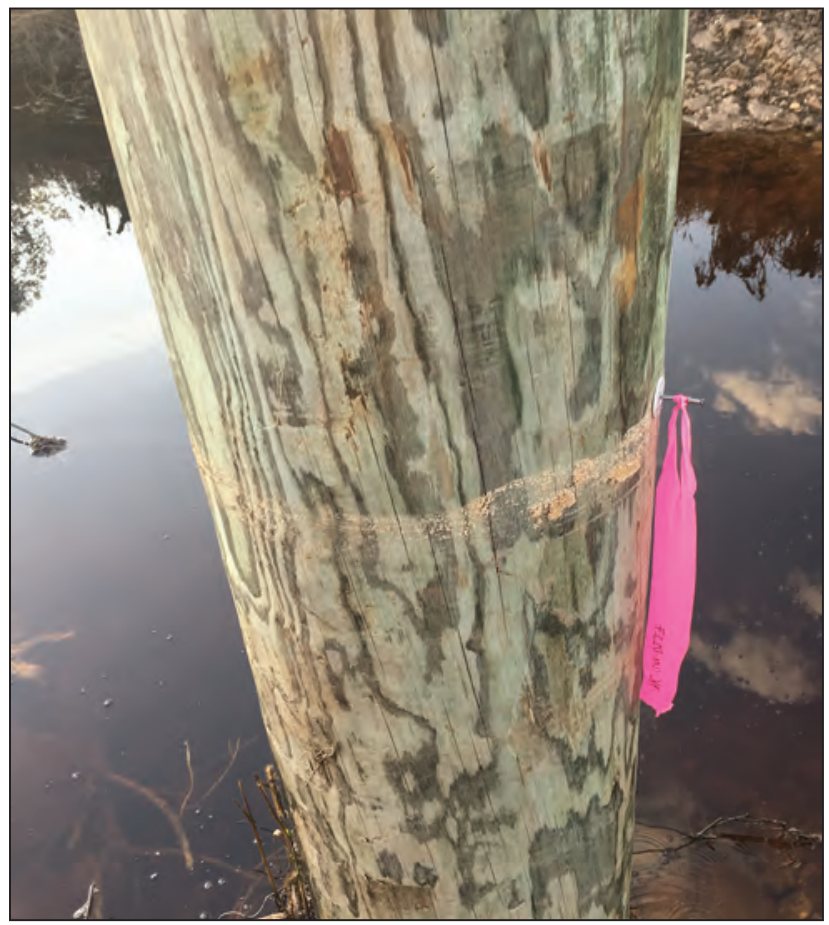

Figure 1-14. Mud line with uncertainty of \pm 0.05 foot. The mud line is well defined but is partially wavy. 


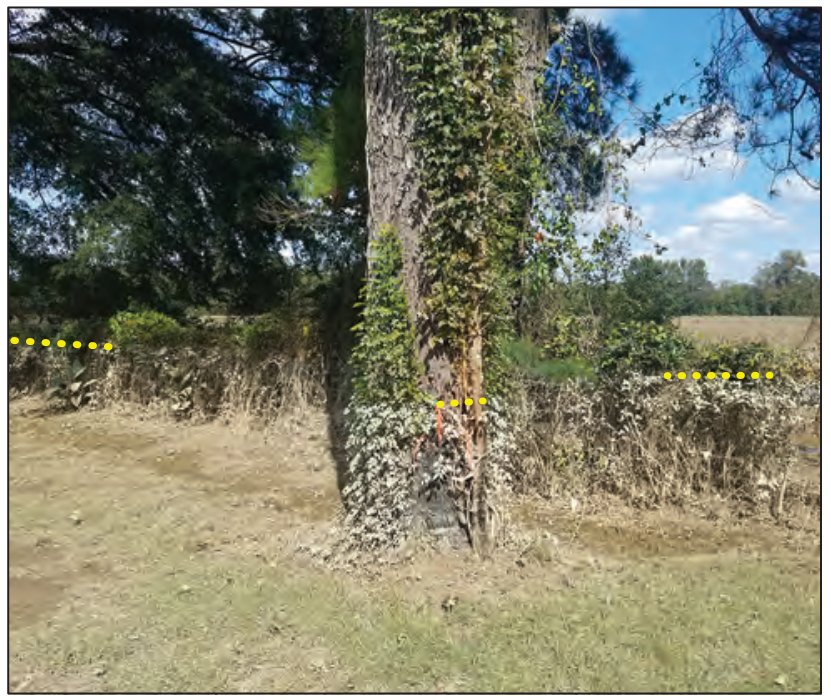

Figure 1-15. Mud line with uncertainty of \pm 0.3 foot. The mud line is clearly visible on the vines on the tree and the vegetation on both sides of the tree. Such mud lines tend to have more uncertainty because of flexibility in the vegetative material. 


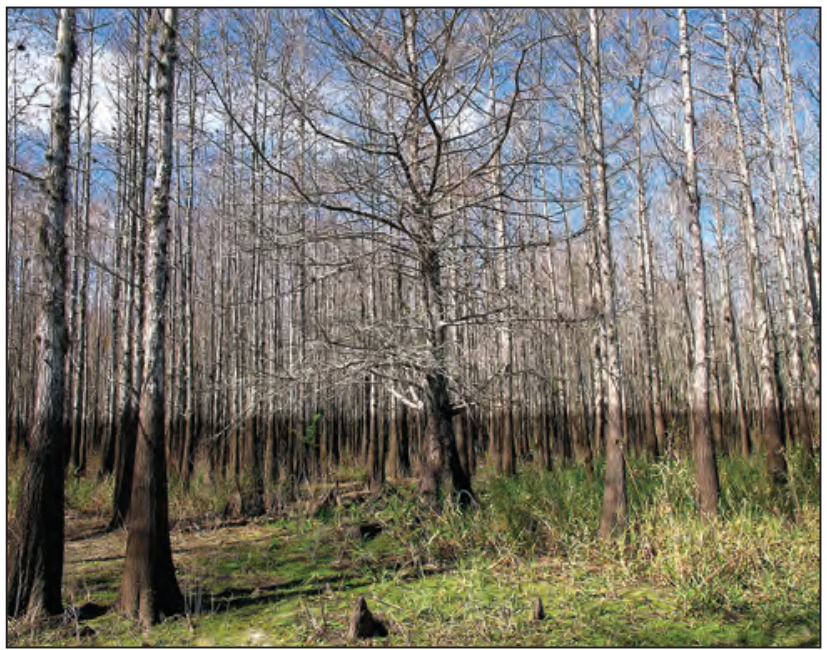

Figure 1-16. The mud lines on the trees show a clear pattern when viewed from a distance; however, high-water marks need to be flagged on individual trees and uncertainty values assigned for each high-water mark. 


\section{Debris Snags}

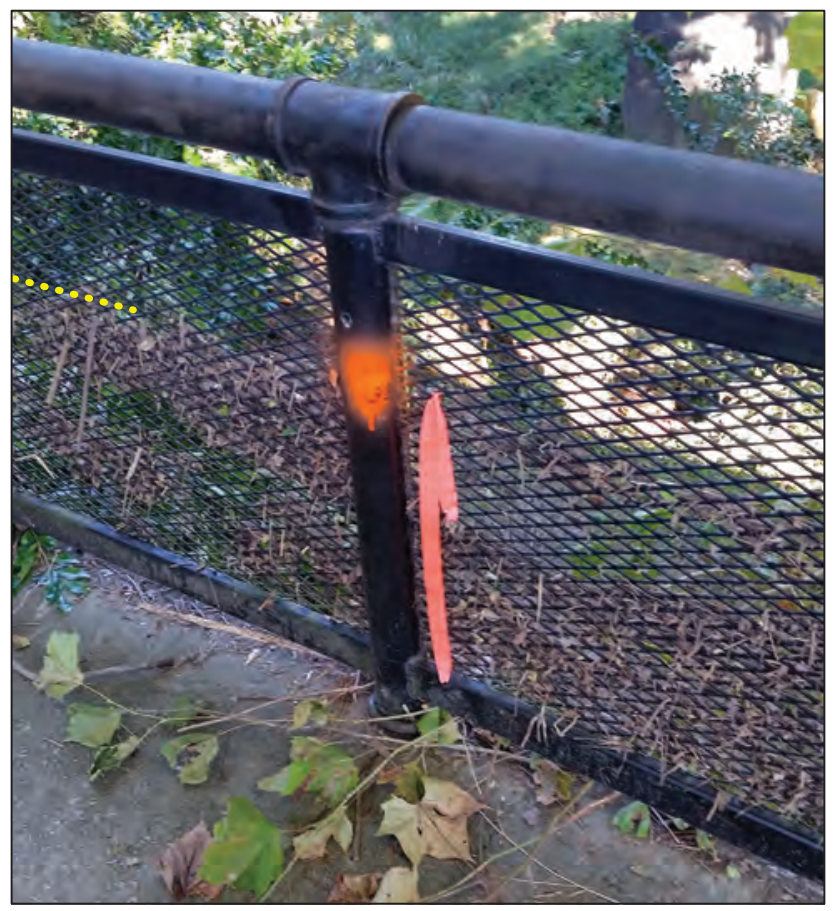

Figure 1-17. Debris snag with uncertainty of \pm 0.05 foot from the knot of the flagging because the highest debris along the debris line appears to be no more than about 0.5 inch higher or lower than that point. 


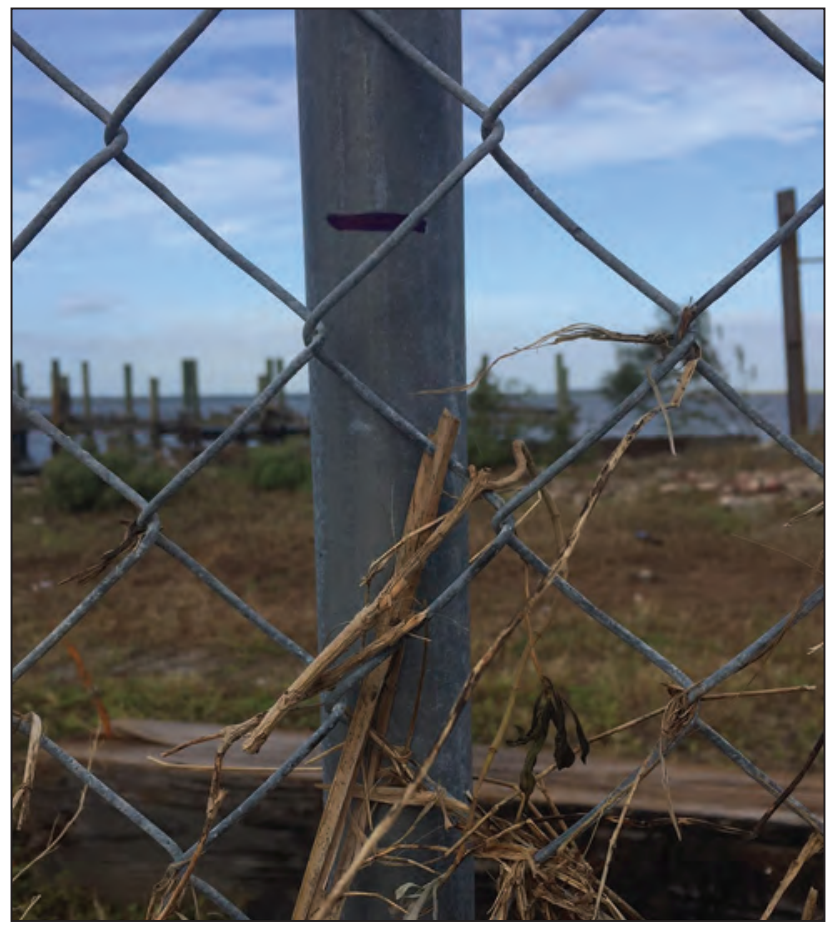

Figure 1-18. Debris snag with uncertainty of \pm 0.1 foot, which is half the distance between the highest row of wire junctions that hold debris and the next highest row of junctions that show no debris. Debris may have collected anywhere along the wire and slid down to the next lowest junction. 


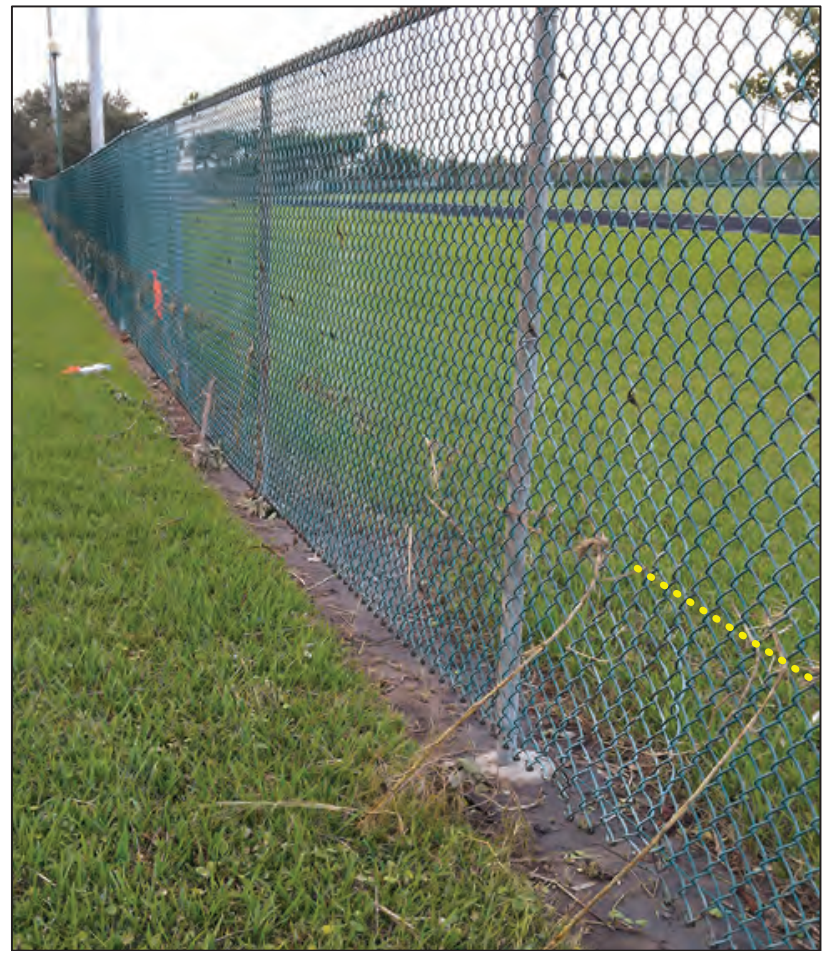

Figure 1-19. Debris snag with uncertainty of \pm 0.2 foot. The line of the debris snag is clear for a distance along the fence. Uncertainty was determined based on the distance between the junctions in the links. 


\section{Debris Lines}

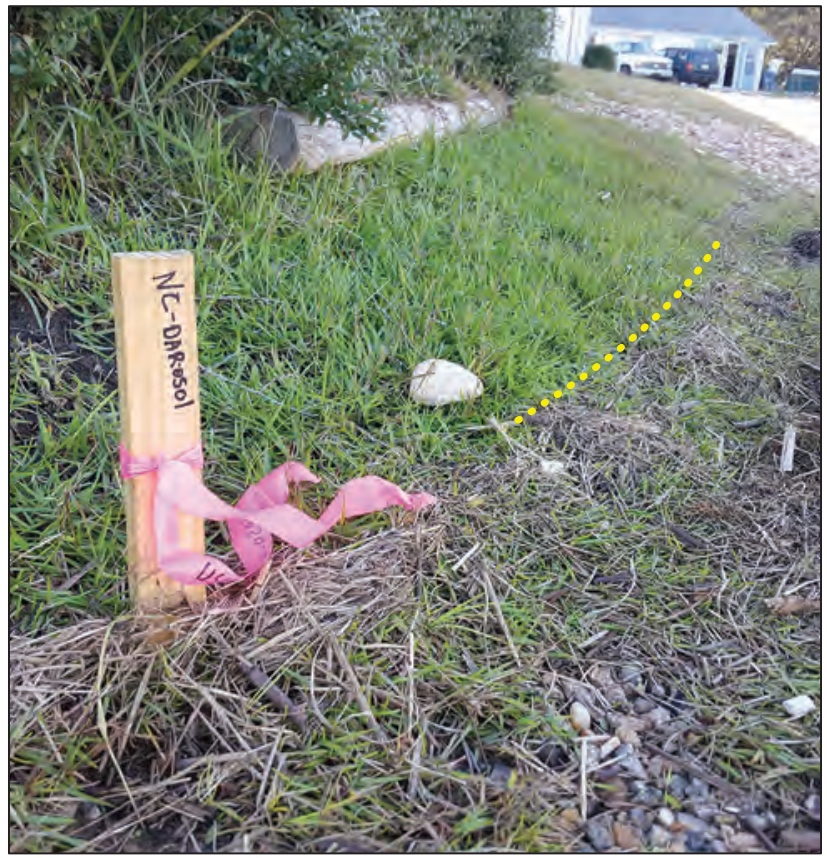

Figure 1-20. Debris line with uncertainty of \pm 0.1 foot. The debris line is fairly consistent. Uncertainty is determined from the slope of the ground and height of the grass. Always look for a hidden seed line in the grass above debris lines like this. 


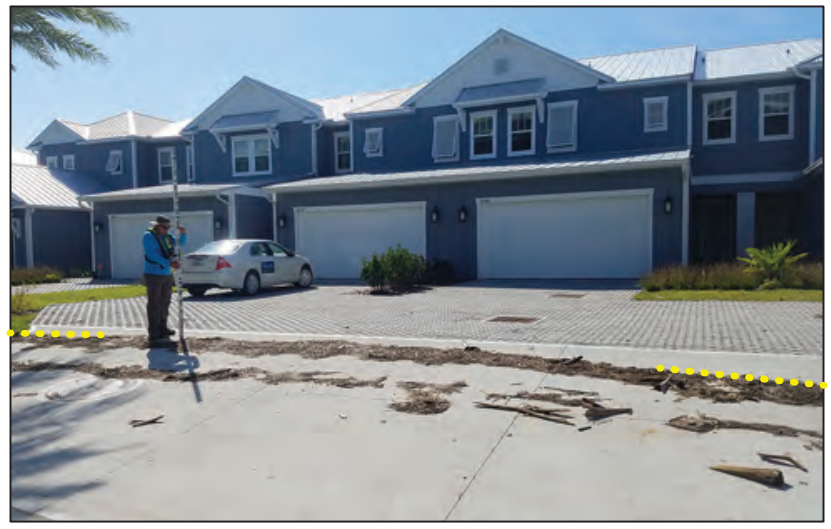

Figure 1-21. Debris line with uncertainty of \pm 0.1 foot. A debris line on a gentle concrete slope can be very reliable, but wave or wind may have caused some waviness and uncertainty. 


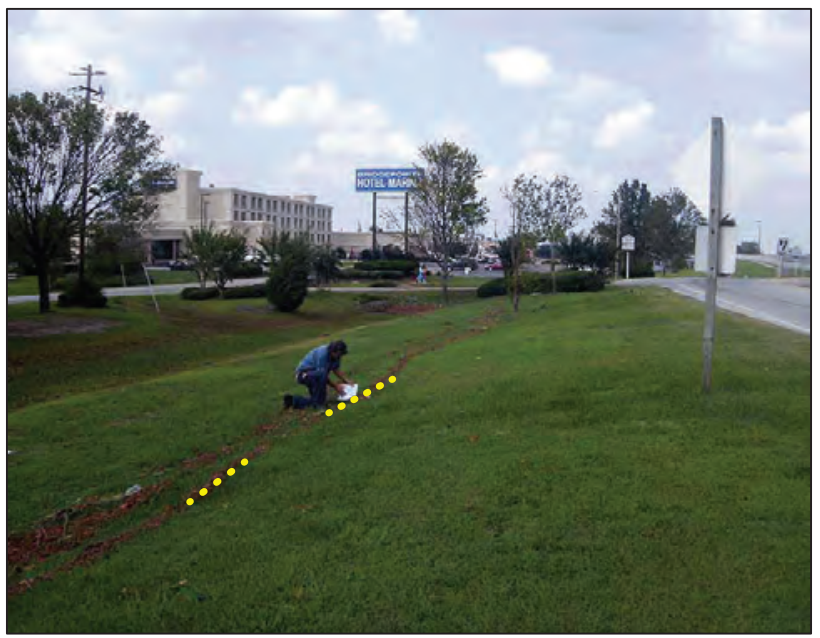

Figure 1-22. Debris line with uncertainty of \pm 0.2 foot. The highwater mark should be determined from the landward side of the debris line. 


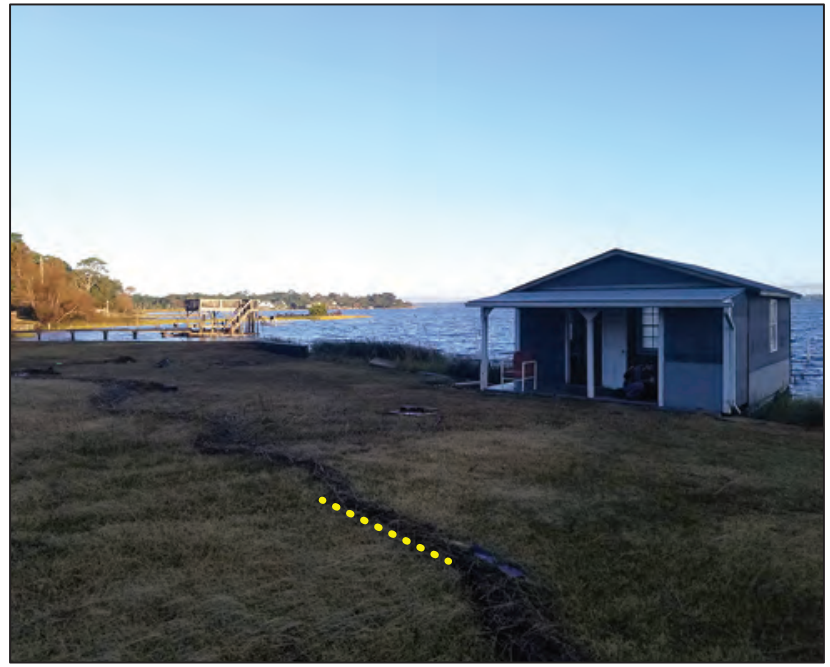

Figure 1-23. Debris line with uncertainty of \pm 0.3 foot. The edge of the debris line on the landward side would indicate the highwater mark. Because wave action on a lake or wide overbank area can push debris higher than the average peak-water surface, the difference in the ground heights on the landward edge of the debris and the lakeward edge can be used to define the uncertainty. 


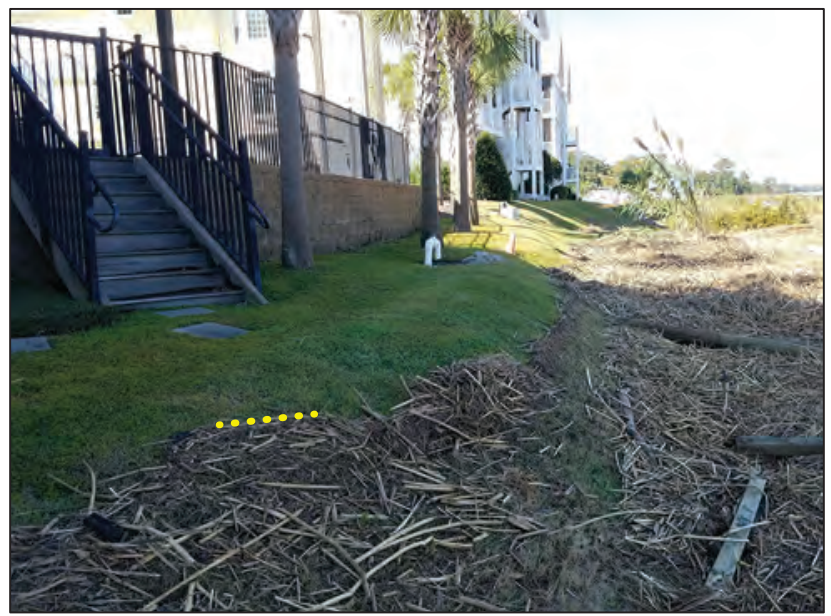

Figure 1-24. Debris line with uncertainty of \pm 1 foot. Although the debris line is distinct, the steep slope in the immediate vicinity may have caused the edge of the debris line to fall lower than the peak-water surface. In some places, it is possible that wind-driven wave action pushed the debris higher. 


\section{Wash Lines}

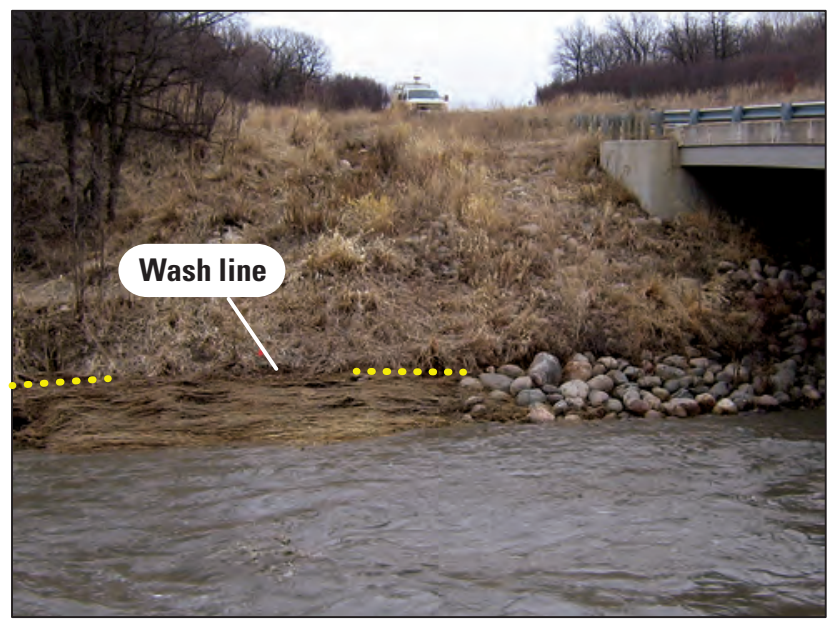

Figure 1-25. Wash line with uncertainty of \pm 0.2 foot. High velocities combed the grasses down along a fairly straight line of about 0.2 feet of elevation variation. 




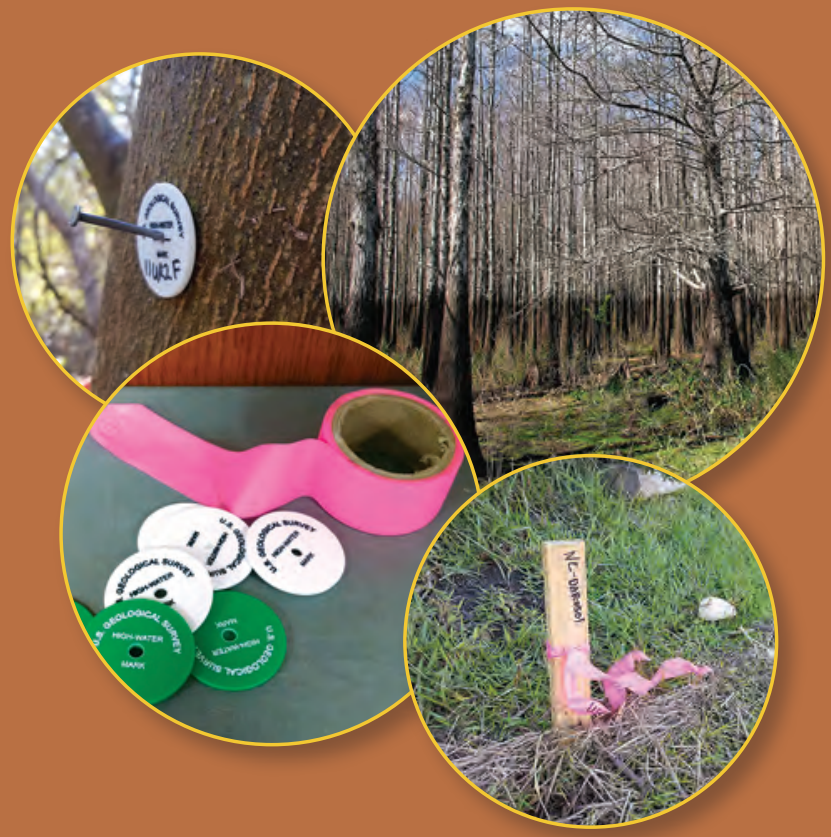

ISSN $0196-1497$ (print)

ISSN 2331-1258 (online)

https://doi.org/10.3133/ofr20171105

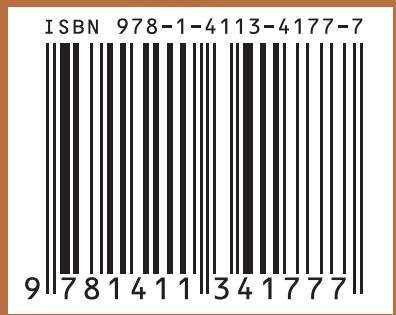

